\title{
Review Article \\ Bacoside A: Role in Cigarette Smoking Induced Changes in Brain
}

\author{
G. Vani, K. Anbarasi, and C. S. Shyamaladevi \\ Department of Biochemistry, University of Madras, Guindy Campus, Chennai 600 025, India \\ Correspondence should be addressed to C. S. Shyamaladevi; cssdevi@gmail.com
}

Received 19 October 2014; Revised 11 January 2015; Accepted 26 February 2015

Academic Editor: Andrea Zangara

Copyright ( 2015 G. Vani et al. This is an open access article distributed under the Creative Commons Attribution License, which permits unrestricted use, distribution, and reproduction in any medium, provided the original work is properly cited.

\begin{abstract}
Cigarette smoking (CS) is a major health hazard that exerts diverse physiologic and biochemical effects mediated by the components present and generated during smoking. Recent experimental studies have shown predisposition to several biological consequences from both active and passive cigarette smoke exposure. In particular, passive smoking is linked to a number of adverse health effects which are equally harmful as active smoking. A pragmatic approach should be considered for designing a pharmacological intervention to combat the adverse effects of passive smoking. This review describes the results from a controlled experimental condition, testing the effect of bacoside A (BA) on the causal role of passive/secondhand smoke exposure that caused pathological and neurological changes in rat brain. Chronic exposure to cigarette smoke induced significant changes in rat brain histologically and at the neurotransmitter level, lipid peroxidation states, mitochondrial functions, membrane alterations, and apoptotic damage in rat brain. Bacoside A is a neuroactive agent isolated from Bacopa monnieri. As a neuroactive agent, BA was effective in combating these changes. Future research should examine the effects of BA at molecular level and assess its functional effects on neurobiological and behavioral processes associated with passive smoke.
\end{abstract}

\section{Introduction}

Cigarette smoking is an intractable and preventable public health problem. It is an important risk factor involved in the pathogenic pathways of a variety of disorders. The WHO has declared global tobacco epidemic and planned "Framework Convention for Tobacco Control" [1]. Tobacco smoke is a toxic air contaminant and secondhand tobacco smoke (SHS) is a formidable health hazard [2]. Epidemiological studies show increased risk for behavioral and cognitive problems and a greater incidence of mental disorders in children exposed to environmental tobacco smoke [3-5]. Prenatal maternal exposure to cigarette smoke has been well documented to induce neurological as well as many other lasting health effects $[6,7]$. Etiological evidences support the involvement of neurotransmitter systems, oxidative and nitrogen stress, mitochondrial dysfunction, and neurogenetic and epigenetic changes in secondhand/passive smoking induced brain changes and the associated pathways have been extensively reviewed [8-11].
Despite the significant health impacts arising from passive smoking, little attention is paid to combat the neurological changes associated with it. This review critically examines and summarizes the study made on the neuroprotective role of $\mathrm{BA}$ in rats exposed to passive cigarette smoke and its sequelae with focus on the neurotransmitter systems, oxidative and lipid peroxidative, mitochondrial dysfunction, and apoptotic changes in rat brain. These results can be integrated with other theories in holistically combating passive smoking induced neurological changes.

\section{Physical and Biochemical Properties of Cigarette Smoke}

Cigarette smoke is divided into two phases: a tar phase and a gas phase. The tar or particulate phase is defined as the material that is trapped when the smoke stream is passed through the Cambridge glass-fiber filter that retains $99.9 \%$ of all particulate material with a size $\sim 0.1 \mathrm{~m}$ [12]. The gas phase is the material that passes through the filter. The particulate 
(tar) phase of cigarette smoke contains $\sim 10^{17}$ free radicals $/ g$, and the gas phase contains $\sim 10^{15}$ free radicals/puff [12]. The radicals associated with the tar phase are long-lived (hours to months), whereas the radicals associated with the gas phase have a shorter life span (seconds) [12-14].

Cigarette smoke that is drawn through the tobacco into an active smoker's mouth is known as mainstream smoke (MS) and the smoke emitted from the burning ends of a cigarette is the sidestream smoke (SS). Mainstream cigarette smoke comprises $8 \%$ of tar and $92 \%$ of gaseous components [12]. Environmental tobacco smoke (ETS) results from the combination of sidestream smoke (85\%) and a small fraction of exhaled mainstream smoke (15\%) from smokers [13]. Importantly, the concentration of numerous toxins is dramatically (up to 100-fold) elevated in SS when compared with MS, and the complex mixture of toxins is attributed rather to a specific component of cigarette smoke to the potential adverse impact of passive smoke on health [15].

Aside from specific chemical constituents, certain physicochemical properties of smoke may participate in disease processes. The $\mathrm{pH}$ of the smoke affects the site and degree of nicotine absorption as well as the smoker's depth of inhalation. The oxidation-reduction state of the smoke is important because oxidants influence the maturation of cholesterol-laden plaques in the coronary arteries and other blood vessels. In short, cigarette smoke is far more than a triad of tar, nicotine, and carbon monoxide [16].

Although SS and MS smoke have qualitatively similar chemical compositions, the respective quantities of individual smoke constituents are different [17]. The exposure to SS smoke depends on the distance from the burning cigarette and conditions of ventilation; the higher concentrations of certain toxic and carcinogenic chemicals in SS smoke result in measurable levels of these chemicals in nonsmokers exposed to ETS [18].

\section{Pharmacodynamics of Smoking}

Although most of the toxicity of smoking is related to other components of cigarette smoke, it is primarily the pharmacologic effects of nicotine that produce the addiction to tobacco. An understanding of how nicotine produces addiction and influences smoking behavior provides a necessary basis for optimal smoking cessation intervention. Cigarette smoke contains $10-14 \mathrm{mg}$ of nicotine [19], of which $1-1.5 \mathrm{mg}$ is absorbed systemically in the lungs through inhalation [20]. Nicotine rapidly enters the pulmonary venous circulation, reaches the brain within $10-20 \mathrm{~s}$, and readily diffuses into brain tissue [21] and binds to nicotine acetylcholine receptors (nAChRs) [22]. Acutely, cigarette smoking induces positive reinforcing effects, including mild euphoria, heightened arousal, reduced appetite, and reduced stress, anxiety, and pain [23].

Nicotine in cigarette smoke is alkaline and readily crosses the blood brain barrier. It mediates the stimulation of mesolimbic dopamine system. It is also involved in modulating other classical neurotransmitters in the brain including catecholamines, serotonin, GABA, and glutamate
[24]. It induces addiction as it shares many properties of psychostimulant drugs such as cocaine and amphetamine [25]. With repeated exposure to nicotine, toxicity gives way to tolerance and addiction. Overtime tolerance is accompanied by increased intake of nicotine to attain the same effects initially taken which leads to physical dependence, compelling higher intake, lest it induces withdrawal symptom. This leads to reinforcement mechanisms, finally leading to addiction [26]. Substances other than nicotine present in cigarette smoke are also involved in mediating the harmful effects in nervous system. Other tobacco smoke constituents affect the structural and functional integrity of blood brain barrier $[27,28]$.

\section{Neuropharmacological Effects of Cigarette Smoking}

Cigarette smoking is an important environmental aging accelerator [29] partly because it induces oxidative stress in multiple organs including the brain and is presented in many diseases, including cognition-related or neurodegenerationrelated pathological changes [30]. This should be presented to demonstrate a direct linkage between smoking and cognitive impairment.

The incidence of cerebrovascular diseases (CVDs) increases with cigarette smoking, as cessation of smoking decreases its incidence [31]. Smoking is a modifiable risk factor for stroke [32] primarily due to hypertension [33]. Other neurological diseases for which smoking is a risk factor include hypoxia, cerebral ischemia, cerebral hemorrhage, brain infarction, subarachnoid hemorrhage, and tardive dyskinesia [34]. Neuroleptic Parkinsonism, resembling Idiopathic Parkinson's disease, is associated with smoking, as higher doses of nicotine exert an inhibitory effect [35]. Cerebral symptoms like brain atrophy and ataxia are exaggerated with smoking [36]. Reports also suggest that cigarette smoking is protective in the development of Parkinson's disease [37] but is an important risk factor in Alzheimer's disease [38], as it accelerates cognitive decline and dementia [39].

\section{Role of Passive Smoking}

The evidence that active smoking is a risk factor for cardiovascular disease (CAD) and the leading cause of preventable death is overwhelming. However, exposure to passive cigarette smoke also exerts detrimental effects on vascular homoeostasis [40]. Importantly, most of these effects appear to be characterized by a rapid onset. For example, the relatively low doses of toxins inhaled by passive smoking are sufficient to elicit acute endothelial dysfunction, and these effects may be related, at least in part, to the inactivation of nitric oxide (NO). Moreover, passive smoking may directly impair the viability of endothelial cells and reduce the number and functional activity of circulating endothelial progenitor cells. In addition, platelets of nonsmokers appear to be susceptible to proaggregatory changes with every passive smoke exposure. Overall, passive smoke induces 
oxidative stress and promotes vascular inflammation. Apart from vasoconstriction and thrombus formation, however, the myocardial oxygen balance is further impaired by adrenergic stimulation and autonomic dysfunction [41]. These data strongly suggest that passive smoking is capable of precipitating acute manifestations as it increases the odds of developing cognitive impairment [42] and 3-fold increase in the risk for dementia, causing neurofibrillary changes depictive of Alzheimer's disease [43].

Hence, one generally overlooked factor contributing to the escalation of tobacco abuse is passive smoking. Nicotine from secondhand smoke exposure results in an increase in plasma nicotine concentration of $\sim 0.2 \mathrm{ng} / \mathrm{mL}$ and amounts to substantial brain $\alpha 4 \beta 2 \mathrm{nAChR}$ occupancy (19\%) in both smokers and nonsmokers compared with $0.87 \mathrm{ng} / \mathrm{mL}$ and $50 \% \alpha 4 \beta 2$ nAChR occupancy from actively smoking one cigarette $[44,45]$. Secondhand smoking is clearly linked to serious illnesses among nonsmokers including asthma, heart disease, sudden infant death syndrome, and cancer [46].

\section{Pharmacological Intervention in Cigarette Smoking}

With the available understanding of the biological effects of cigarette smoking many treatment strategies are available. The primary target is nicotine; hence nicotine replacement therapy or nicotine substitution in the form of chewing gums, transdermal patch, and spray are employed in smoking cessation aid [47-49]. Other pharmacological therapies include receptor antagonists and nicotinic antagonists (mecamylamine and chlorisondamine) [50]; opiate antagonists and naloxone and naltrexone [51]; nonreceptor antagonists [52]; serotonin uptake inhibitors (zimelidine and citalopram) and monoamine oxidase inhibitor [53]; and antidepressants [54, 55]. Angiotensin converting enzymes (ACE) inhibitors and calcium antagonists are also effective in combating smoking induced toxicity [56]. These drugs are mainly indicated to reduce the severity of tobacco withdrawal, but not as an aid to stop smoking [57].

Currently, the first line therapy for smoking cessation includes bupropion (amfebutamone), an atypical antidepressant that inhibits norepinephrine uptake and dopamine uptake [58]. The metabolite of bupropion, $(2 S, 3 S)$ hydroxybupropion, is an antagonist on the $\alpha 4 \beta 2$ (nAChR) [59]. Another agent is varenicline, which is a highly selective partial agonist of the $\alpha 4 \beta 2$ (nAChR) that stimulates dopamine release in the nucleus accumbens (nAC) but to a much less extent than nicotine itself [60].

These interventions are improbable and ineffective in rendering protection against secondhand smoke. Due to poor pharmacological management of passive smoking, it was hypothesized that intervening with a neuroactive agent can prevent or minimize neurological changes. Studies on supplementation with vitamins E, C, and A [61, 62]; antioxidants: glutathione, $\mathrm{N}$-acetyl cysteine, and superoxide dismutase [63]; and fish oil, curcumin, and green tea [64-66] have reported to offer protection against smoking induced damages.
In this context, this study evaluated the effect of BA, an active constituent isolated from Bacopa monnieri against smoking induced damages in rat brain. Bacopa monnieri exerts neuropharmacological effects [67] and is effective in the treatment of mental illness and epilepsy [68]. Its biological effects include free radical scavenging [69]; vasodilatory [70, 71]; and mast cell stabilizing [72] activities. The various biological activities of BA have been reviewed in detail [73, 74].

Bacoside A is 3-(a-L-arabinopyranosyl)-O-b-D-glucopyranoside-10, 20-dihydroxy-16-keto-dammar-24-ene [75] and is the major chemical entity responsible for neuropharmacological effects and the nootropic action or antiamnestic effect of Bacopa monniera. Bacoside A cooccurs with bacoside B, the latter differing only in optical rotation and is probably an artefact produced during the process of isolating BA [76]. On acid hydrolysis, bacosides yield a mixture of aglycones, bacogenins A1, A2, and A3 [77], which are artefacts, two genuine sapogenins, jujubogenin and pseudojujubogenin, and bacogenin A4, identified as ebelin lactone pseudojujubogenin [78].

\section{Methods}

7.1. Isolation of Bacoside A. The plant Bacopa monniera was collected in and around Chennai, India, and authenticated by Dr. P. Brindha, Central Research Institute (Siddha), Chennai, India. The dammarane type triterpenoid saponin BA was isolated from the plant by the standard procedure. The purity of the isolated BA was identified by thin layer chromatography (TLC) and infrared (IR) spectrum analysis using standard BA [79].

7.2. Experimental Setup. Adult male albino rats of Wistar strain $(120-200 \mathrm{~g})$ were used for the present study. The rats were provided with standard pelleted rat feed and water ad libitum. They were acclimatized to the laboratory conditions and maintained under $12 \mathrm{~h}$ light and dark cycles. The experiments were carried out in accordance with the guidelines provided by the Institutional Animal Ethical Committee [79].

The animals were divided into four groups of 6 animals each. Group I: control. Group II (CS): rats exposed to cigarette smoke. Group III (BA): rats administered with BA $(10 \mathrm{mg} / \mathrm{kg}$ bw/day, p.o.). Group IV (CS + BA): rats exposed to cigarette smoke and simultaneously administered with BA. Group II and Group IV rats were exposed to cigarette smoke, following a standard method as described [79] for a period of 12 weeks.

The rats were exposed to side stream cigarette smoke in whole body smoke exposure chamber. The rats were exposed twice daily as described $[80,81]$. The experimental period lasted for 12 weeks. Drug control animals received aqueous suspension of BA in $1 \%$ gum acacia orally at a dosage of $10 \mathrm{mg} / \mathrm{kg}$ bw/day for 12 weeks, whereas experimental animals exposed to cigarette smoke (Scissors Standard Cigarette) were simultaneously administered with BA at the same dose. Control animals received a corresponding volume of the vehicle suspended in normal saline. The same brand of locally 
TABLE 1: Constituents of the cigarette smoke.

\begin{tabular}{lc}
\hline Smoke constituents & Concentration/cigarette \\
\hline Nicotine & $1.8 \mathrm{mg}$ \\
Carbon monoxide & $20 \mathrm{mg}$ \\
Total particulate matter & $32 \mathrm{mg}$ \\
Acetaldehyde & $0.9 \mathrm{mg}$ \\
Hydrogen cyanide & $225 \mathrm{mg}$ \\
Benzene & $38 \mathrm{mg}$ \\
N'nitrosonorcotine & $240 \mathrm{mg}$ \\
\hline
\end{tabular}

available cigarette was used throughout the experiment (Scissors Standard, W.D \& H.O.Wills, Hyderabad Deccan Cigarette Factory). Control animals were subjected to the same handling and time in the smoke exposure chamber with air replacing smoke/air mixture. The composition of cigarette smoke was analyzed at Tamil Nadu Pollution Control Board, Chennai, and the constituents present are listed in Table 1.

\section{Results and Discussion}

8.1. Structural Brain Changes and Clinical Correlates. Cigarette smoking is associated with diverse structural changes in brain, probably as a consequence of toxicity or as an adaptive response, causing a reduction in integrity of cerebral white matter microstructure [82] and gray matter volumes $[83,84]$ and these changes appear correlated with the magnitude of cigarette exposure. Smoking induced structural changes in brain are associated with cognitive deficits [85] as well, with the integrity of white matter and glial proliferation [86]. In gross, the microstructural changes in key brain regions and white matter tracts have a negative impact in cigarette smokers.

In the present study, histological changes were prevalent in brain of rats exposed to cigarette smoke that were inflammatory and edematous in the cerebrum (Figure 1). Smoking induced inflammatory changes were also marked by increased activity of CK-MB isoenzyme in serum [79], an early marker for pathological changes like cerebral damage [87]. 4-N-Methyl-N-nitrosamino-1-(3-pyridyl)1-butanone (NNK), is a major nitrosamine present in substantial concentration in MS and SS that causes oxidative stress and triggers neuroinflammation in brain $[88,89]$. Inflammation plays a pivotal role in extremely wide array of disease conditions ranging from viral diseases of CNS to neurodegenerative disorders. NKK mediated microglial activation leads to profound increase in inflammatory mediators. The inflamed milieu may cause neuronal damage [90]. A decrease in the inflammatory changes was noted in BA treated rats exposed to cigarette smoke, which could be due to the anti-inflammatory effect of BA [91] and the reduction in cerebral inflammatory changes in treated rats were also reflected in lowered levels of CK-MB as against untreated rats [79].

Electroencephalography (EEG) of rat brain monitored frontal and parietal regional changes in brain as electrical changes as $\alpha, \beta, \delta$, and $\theta$ waves. Cigarette smoke exposed rats presented depressed $\delta$ and increased $\alpha$ waves (Figure 2). A desynchronized and electrically active EEG pattern is noted in smokers [92]. Acute smoking accelerates dominant frequency fast waves $\alpha$ and $\beta$ with a reduction in slow wave $\delta$ and $\theta$ waves illustrate a stimulant action [93], whereas chronic smoking induces less $\alpha$ wave and more $\beta$ wave [94]. In rats treated with BA and exposed to cigarette smoke, the EEG pattern was devoid of desynchronization and lacked stimulatory wave, an effect also noted among cholinergic agonists: mecamylamine and scopolamine. This shows the anticholinergic effect of BA and effective against smoking induced stimulation of brain.

8.2. Neurotransmitter Systems. Neurotransmitters mediate diverse pharmacological effects on central and peripheral nervous system and participate in reinforcing, mood elevation, and cognitive functions [95]. A balance in their rate of synthesis and utilization constitutes the regulatory mechanism in neurotransmission. Smokers have positive effects like pleasure, arousal, and relaxation, as well as negative effects like depression and anxiety. The functional antagonism presented in cigarette smoking is related to desensitization of nAChR. Nicotine in cigarette smoke upregulates $\mathrm{nAChR}$ (pre- and postsynaptic), which in turn interacts with the noradrenergic, cannabinoid, dopaminergic, cholinergic, and serotonergic systems [96] and increases the levels of norepinephrine, dopamine, acetylcholine, and serotonin [97].

Cigarette smoking upregulates $\mathrm{nAChR}$ in the brain, including the common $\alpha 4 \beta 2^{*}$ nAChR subtype [23]. In the present study, an upregulation of $\alpha 4$ subunit was evident in rats exposed to cigarette smoke (Figure 3 ). Chronic administration of nicotine also upregulates nAChRs $[98,99]$ causing an increased receptor function and sensitivity to nicotine. This results in increased trafficking of nAChRs to the cell surface, increased receptor assembly and/or maturation, or other mechanisms [100]. In smokers, abstinence from smoking normalizes the $\mathrm{AAChR}$ upregulation to the levels of nonsmokers [101, 102]. Similarly, commonly used treatments for smoking cessation also decrease $\alpha 4 \beta 2^{*} \mathrm{nAChR}$ to near normal levels as in nonsmokers. In the exploratory analyses, decreases in $\alpha 4 \beta 2^{*} \mathrm{nAChR}$ levels are associated with decrease in the perceived rewarding properties of nicotine $[103,104]$. Hence a downregulation of $\alpha 4 \mathrm{nAChR}$ in BA treated smoke exposed rats could be associated with diminished reward from cigarettes (presumably mediated at least in part through dopamine release). Taken together, these findings indicate that the role of $\mathrm{BA}$ on $\mathrm{nAChR}$ regulation could be vital in modulating nicotine response and reward pathway in chronic cigarette smoking. However, the mechanism on how BA influences the upregulation remains to be understood.

Nicotine is cholinergic by increasing the release of acetylcholine (ACh) from axonal stores and inhibits its clearance by inhibiting acetylcholine esterase (AChE) [105-107]. Increased accumulation of $\mathrm{ACh}$ increases the electrical activity in rat brain [107]. This accounts for the increase in most of the neurotransmitters in rats exposed to cigarette smoke (Figures 4-6). In BA treated rats, the activities of AChE were increased 


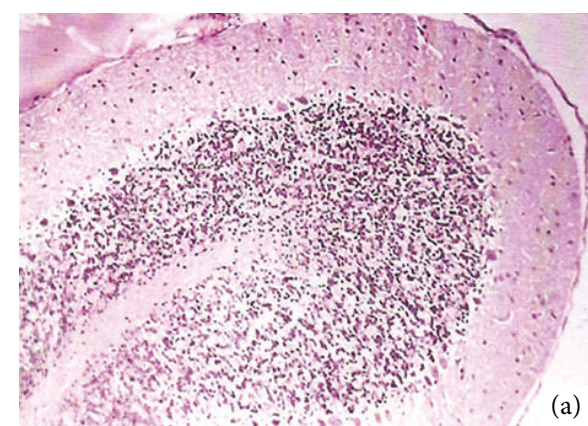

$(\mathrm{H} \& \mathrm{E}, \times 10)$

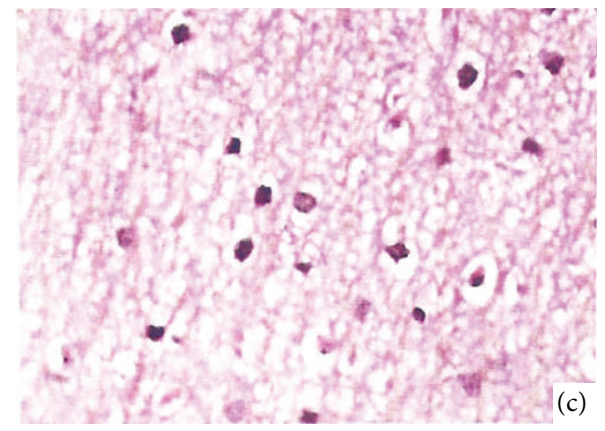

$(\mathrm{H} \& \mathrm{E}, \times 40)$

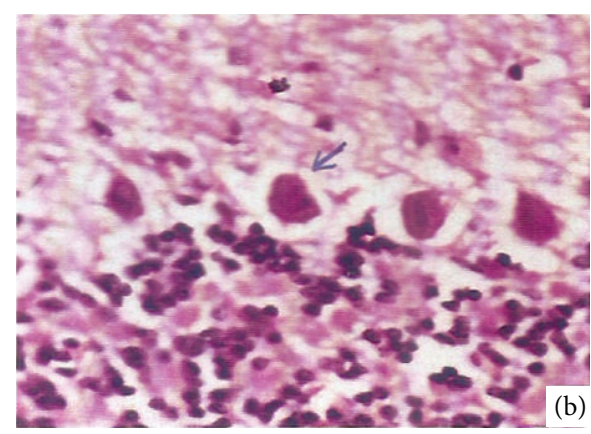

$(\mathrm{H} \& \mathrm{E}, \times 40)$

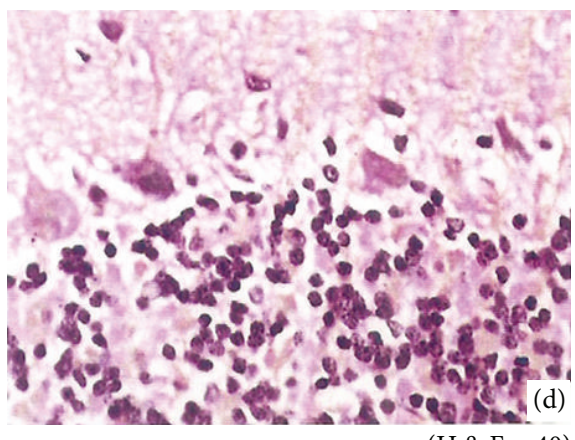

$(\mathrm{H} \& \mathrm{E}, \times 40)$

FIGURE 1: Sections of rat brain cerebellum. (a) Control rats showing normal architecture. (b) CS rats showing mild gliosis, edema, necrosis, and Purkinje cell damage. (c) BA rats showing normal architecture with no significant changes. (d) CS + BA rats showing normal morphology of Purkinje cells.

\begin{tabular}{|c|c|c|c|c|}
\hline & 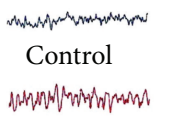 & 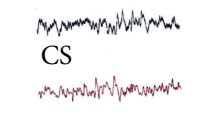 & 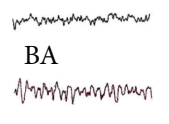 & 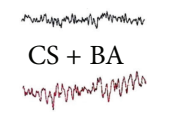 \\
\hline$\beta$ & $\begin{array}{l}\text { Control } \\
\text { whflphatph }\end{array}$ & 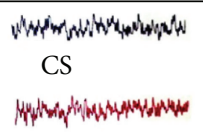 & BA & 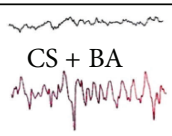 \\
\hline$\delta$ & 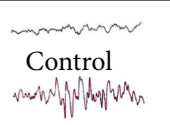 & 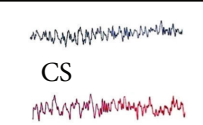 & BA & CS + BA \\
\hline$\theta$ & Control & 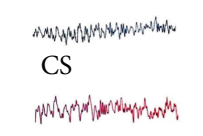 & 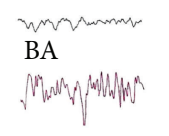 & $\mathrm{CS}+\mathrm{BA}$ \\
\hline
\end{tabular}

- Parietal regions
Frontal regions

FIGURE 2: Electroencephalographic pattern of frontal and parietal regions of rat brain.

(Figure 7), which could have decreased the lowered levels of ACh. This confirms the anticholinergic effect of BA [108].

Increases in plasma catecholamines are known to occur with smoking [109]. Upregulation of $\mathrm{nAChR}$ increases the release of catecholamines: epinephrine and norepinephrine, an effect mediated through the tyrosine hydroxylase activity [110]. Vasoconstrictor effects observed in smoking are related to increases in norepinephrine [111]. In the present study, smoking induced an increase in the levels of epinephrine and norepinephrine in rat brain (Figure 8). However, BA administration maintained the levels of norepinephrine in treated rats. The observed lowering could be due to the downregulation of $n A C h R$ by BA. Apart from its ability to induce downregulation of $\mathrm{nAChR}$ expression, BA could have interacted with tyrosine hydroxylase [112] and modulated the release of catecholamines.

Nicotine also influences the release of serotonin, and it has been reported to have a dual role as it induces both an increase and decrease $[113,114]$. In the present study, cigarette smoking increased the serotonin level in rats. Serotonergic dysfunction has also been in smokers [115]. Serotonergic dysfunction is associated with clinical depression and depression is far more prevalent among smokers [116] suggesting a possible link. Further, compounds that increase dopamine and its metabolites concentration have abuse potential like opiates and cocaine, whereas those which lower dopamine induce cognitive, behavioral, and motor coordination defects [117]. The role of BA on serotonin [118] could have maintained the levels in treated animals (Figure 8). Physiologically, high level of neuronal dopamine induces greater oxidative stress derived from dopamine [119]. These results confirm the effect of Bacopa monnieri extract in normalizing norepinephrine, serotonin, and dopamine in cortex and hippocampus of rats, in both acute and chronic unpredictable stress [120]. In the cigarette smoke exposed rats, an increase in dopamine levels was observed, but in BA administered rats the levels 

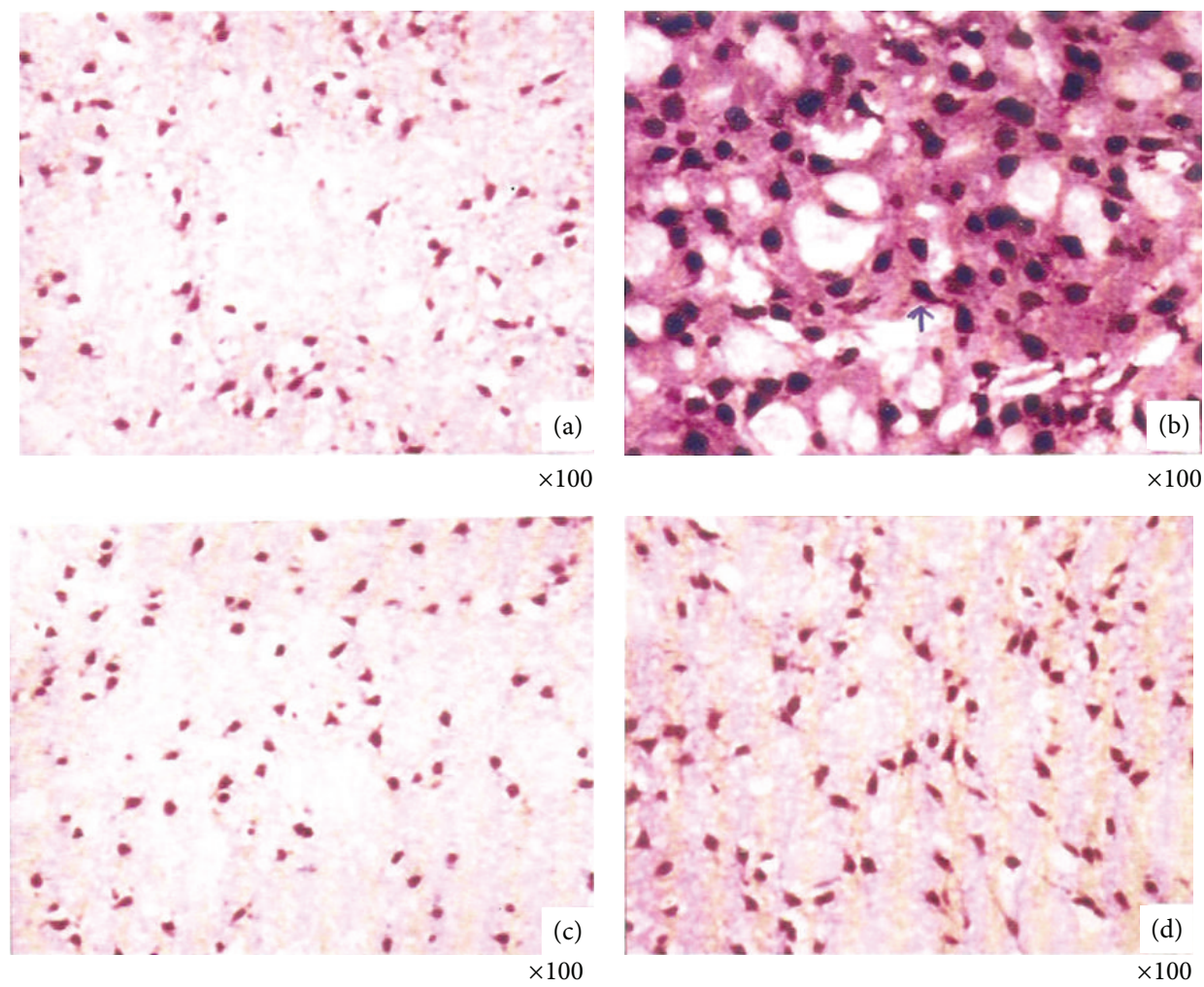

Figure 3: Immunohistochemical analysis of nAChR $(\alpha 4)$ expression in rat brain cerebellum. (a) Control rats showing normal expression of nAChR. (b) CS rats showing increased expression of nAChR. (c) BA rats showing normal expression of nAChR. (d) CS + BA rats showing decreased expression of nAChR.

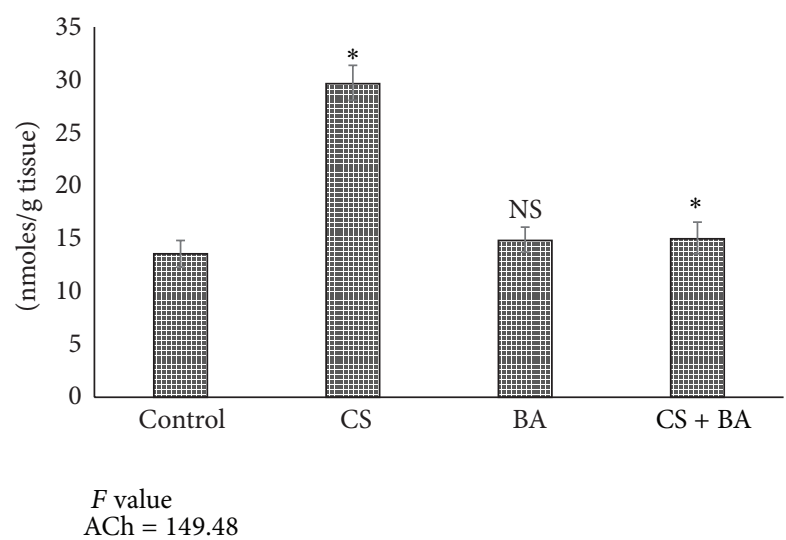

FIGURE 4: Levels of acetylcholine in brain of control and experimental animals. Values are expressed as Mean \pm S.D. Significance is indicated for comparisons between control and CS and BA; Group CS versus CS + BA with Dunnett's T3 post hoc multiple comparison test; ${ }^{*} P<0.001$; NS: nonsignificant.

were maintained at near normal. This reflects the safety and subsequent tolerability of BA in preclinical models as it did not induce any untoward and toxic effect.

Most of the nicotine-mediated release of neurotransmitters occurs via modulation by presynaptic nAChRs, although direct release of neurotransmitters also occurs [121].
Dopamine release is facilitated by nicotine-mediated augmentation of glutamate release and with long term treatment, by the inhibition of GABA release [122]. In addition to direct and indirect stimulation of neurotransmitter release, chronic cigarette smoking (but not nicotine administration) reduces brain monoamine oxidases $\mathrm{A}$ and $\mathrm{B}$ (MAO-A and MAO-B) activity, which would be expected to increase monoaminergic neurotransmitter levels such as dopamine and norepinephrine in synapses, thus augmenting the effects of nicotine and contributing to addiction [123]. Inhibition of MAO facilitates acquisition of nicotine self-administration in rats, supporting the idea that MAO inhibition interacts with nicotine to reinforce tobacco dependence [124]. Decreased activity of MAO in cigarette smoking exposed rats (Figure 8) confirms reports that have shown downregulation of MAO expression, including MAO-A and MAO-B in the brain, $[125,126]$ as well as influencing methylation of MAO promoter genes [127]. This lowering could have resulted in an increase in dopamine content in cigarette smoke exposed rats. Increases in MAO activities in BA treated rats (Figure 8) confirm the reports of recent studies which have shown the influences of Bacopa monnieri on the activities of MAO [128].

Polyamines play a key role in brain cell replication, differentiation, and regulation of nAChRs and they influence synaptic transmission $[129,130]$. Alterations in polyamine gating of cholinergic synaptic signaling contribute to adverse neurobehavioral effects of numerous neuroteratogens [130]. 


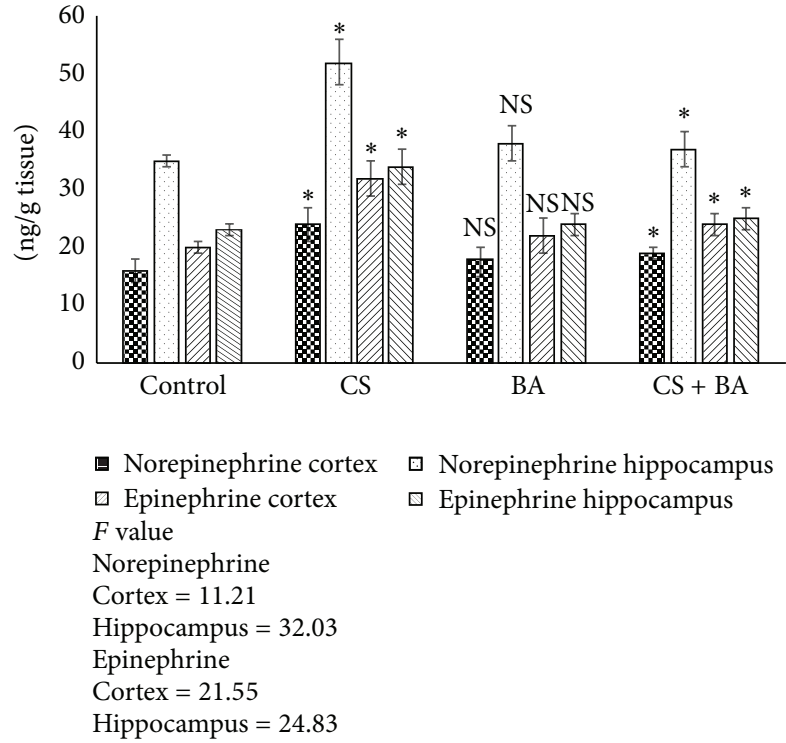

FIGURE 5: Levels of norepinephrine and epinephrine in brain of control and experimental animals. Values are expressed as Mean \pm S.D. Significance is indicated for comparisons between control and CS and BA; Group CS versus CS + BA with Dunnett's T3 post hoc multiple comparison test; ${ }^{*} P<0.001$; NS: nonsignificant.

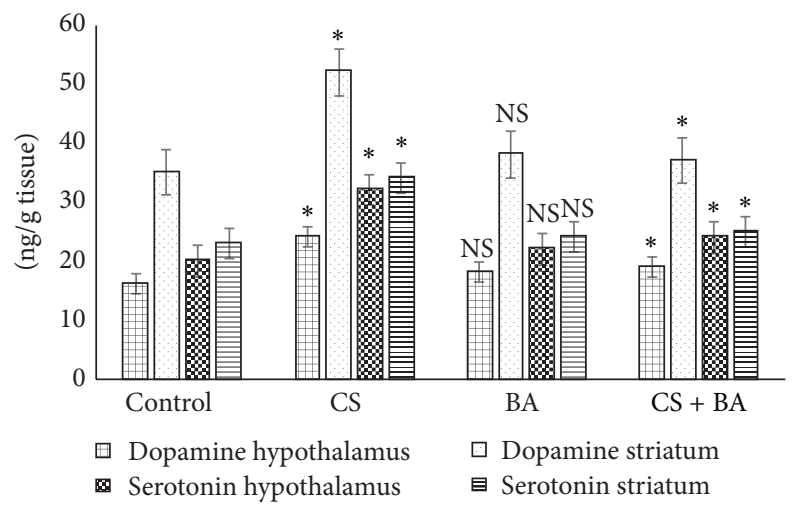

Figure 6: Levels of dopamine and serotonin in brain of control and experimental animals. Values are expressed as Mean \pm S.D. Significance is indicated for comparisons between control and CS and BA; CS versus CS + BA with Dunnett's T3 post hoc multiple comparison test; ${ }^{*} P<0.001$; NS: nonsignificant.

Ornithine decarboxylase (ODC) is the rate limiting enzyme in the maintenance of polyamine levels. Inhibition of ODC inhibits growth and induces gross dysmorphology, upregulating the $\alpha 7$ and $\alpha 4 \beta 2^{*} \mathrm{nAChR}$. This is accompanied by abnormalities in macromolecular indices of cell packing density and cell membrane surface area. In chronic cigarette smoking exposed rats, ODC activity increased significantly (Table 2).

Excitotoxic challenge induces neuronal proliferation and induces ODC [131]. Induction of ODC is neuroprotective in cerebral ischemia [132], and, however, is also a common response in various pathological stimuli in brain such as

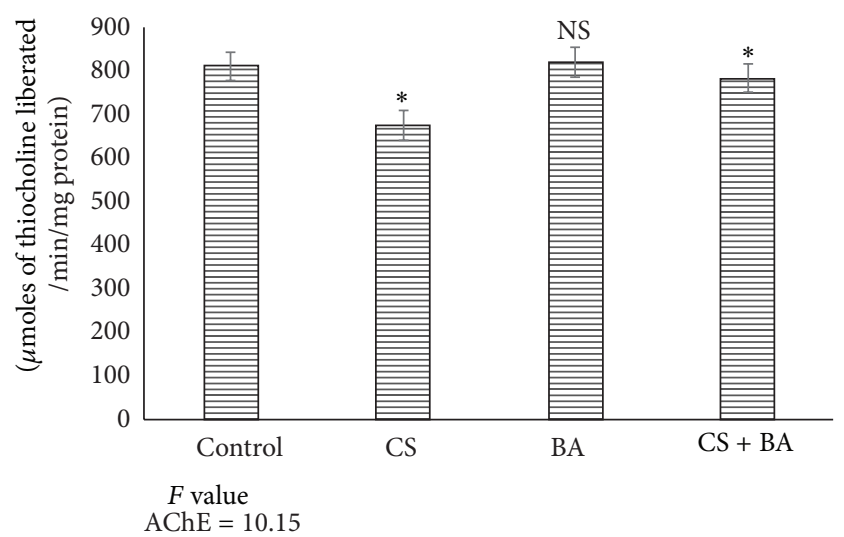

FIGURE 7: Activities of acetylcholine esterase (AChE) in brain of control and experimental animals. Significance is indicated for comparisons between control and CS and BA; CS versus CS + BA with Dunnett's T3 post hoc multiple comparison test; ${ }^{*} P<0.001$; NS: nonsignificant.

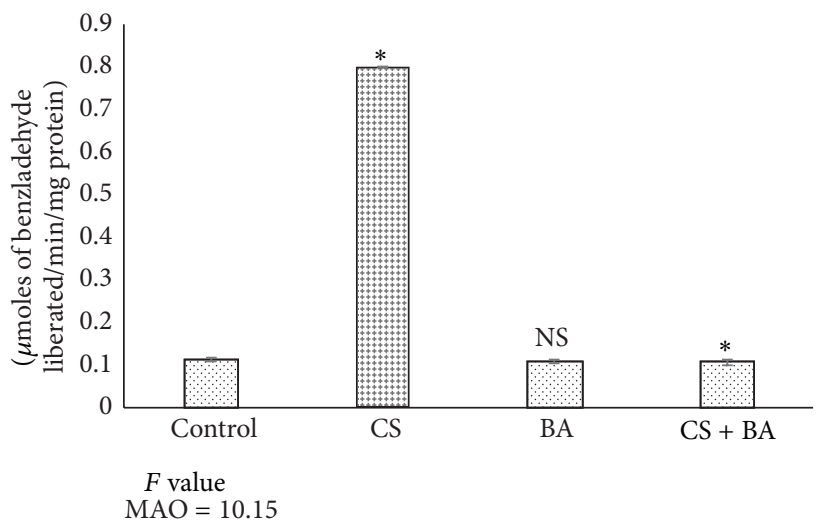

FIGURE 8: Activities of monoamine oxidase (MAO) in brain of control and experimental animals. Significance is indicated for comparisons between control and CS and BA; Group CS versus CS + BA with Dunnett's T3 post hoc multiple comparison test; ${ }^{*} P<0.001 ;$ NS: nonsignificant.

physical, chemical, thermal, and metabolic injuries [133]. A relatively long lasting increase in ODC and consequently its product putrescine are causally related to neurodegeneration [134]. In the present study, cigarette smoking increased the activities of ODC. BA treated rats recorded a decrease in ODC activity confirming its role in inhibiting neurodegenerative process following cigarette smoking induced excitotoxicity in brain.

8.3. Nicotine and Cotinine Levels. Cigarette smoking increases the levels of nicotine and its metabolite cotinine to pharmacologically active concentrations that are responsible for mediating the aspects of nicotine dependence. In rats exposed to cigarette smoke, accumulation of cotinine in brain was noted (Table 3), and the levels were lowered in BA treated rats. The decrease in the levels could have probably resulted from the increased clearance of cotinine by the 
TABLE 2: Levels of nicotine and cotinine in brain of control and experimental animals. Values are expressed as Mean \pm S.D.

\begin{tabular}{|c|c|c|c|c|c|}
\hline Parameter & Control & $\begin{array}{l}\text { Cigarette smoke } \\
\text { (CS) }\end{array}$ & $\begin{array}{l}\text { Bacoside A } \\
\text { (BA) }\end{array}$ & $\begin{array}{l}\text { Cigarette smoke + bacoside A } \\
(\mathrm{CS}+\mathrm{BA})\end{array}$ & $F$ value \\
\hline $\begin{array}{l}\text { Nicotine (ng/g } \\
\text { tissue) }\end{array}$ & n.d & $180 \pm 12$ & n.d & $89 \pm 5^{*}$ & 870.08 \\
\hline $\begin{array}{l}\text { Cotinine (ng/g } \\
\text { tissue) }\end{array}$ & n.d & $210 \pm 15$ & n.d & $120 \pm 8^{*}$ & 718.14 \\
\hline
\end{tabular}

Significance is indicated for comparisons between control and CS and BA; CS versus CS + BA with Dunnett's T3 post hoc multiple comparison test; ${ }^{*} P<0.001$. n.d: not detected.

CYP system. Although Bacopa monnieri extract reportedly inhibits CYP enzymes [135], increased clearance of cotinine, as noted from a decrease in cotinine levels in BA treated rats, confirms that purified bacosides do not inhibit CYP; instead, the constituents in crude extract exert an inhibitory effect $[136,137]$.

Cigarette smoking accelerates the metabolism of drugs, especially the ones primarily metabolized by CYP1A2 [138]. It delays the clearance of nicotine [139]. In smokers, nicotine clearance is increased by $14 \%$ in 4 -day smoking abstinence and by $36 \%$ higher in 7-day smoking abstinence compared to overnight abstinence. Apart from nicotine, substance(s) in cigarette smoke, as yet unidentified, also affect the metabolism of nicotine. For instance, cotinine slows the metabolism of nicotine since both are metabolized by the same enzyme [140]. However, carbon monoxide in cigarette smoke has no effect on nicotine and cotinine clearance [141], but $\beta$-nicotyrine, a minor alkaloid in cigarette smoke, effectively inhibits CYP2A6 in vitro [142]. Thus, reduced nicotine clearance may also result from downregulation of CYP expression and not inhibition [143].

Cigarette smoking also induces glucuronidation of some drugs, such as propranolol and oxazepam, and UGT1A9 is the inducible component of $3^{\prime}$-hydroxycotinine O-glucuronidation [143]. Excretion of $3^{\prime}$-hydroxycotinine O-glucuronide is induced by smoking, but the extent of nicotine and cotinine $\mathrm{N}$-glucuronidation is not significantly affected. In rats exposed to cigarette smoke increase in UDP-GT was noted and the activities remained unaltered in BA treated rats [144]. The adaptogenic role of Bacopa monnieri is evident from increased cotinine clearance [145].

8.4. Oxidative and Peroxidative Changes. Free radicals mediated oxidative stress has been implicated in the pathogenesis of smoking-related diseases and antioxidant nutrients are reported to prevent the oxidative damage induced by smoking. Cigarette smoking modulates antioxidant status in various organs by increasing lipid peroxidation and prooxidative state [146]. Increased basal and induced lipid peroxidation were observed in cigarette smoke exposed rat brain [147]. Acute exposure to cigarette smoke enhances the production of antioxidant enzymes as a result of adaptive response that mitigates the damage [148], but chronic exposure decreases the inherent antioxidant defense in brain $[149,150]$.

The constituents of cigarette smoke affect the individual cellular antioxidants differently. The quinone/semiquinone radicals from the tar phase of cigarette smoke inactivate superoxide dismutase [151] and inhibit catalase in brain [152]. Acetaldehyde, a major aldehyde from the smoke, depletes cell of cellular glutathione [153]. Other cellular antioxidants, tocopherols, carotenoids, and retinol, are destructed by cigarette smoke [154].

Further the cigarette tar contains large amounts of metals, complexed to some components of tar such as odiphenols [155], which can mobilize reactive iron from ferritin and copper from copper binding protein inducing damage to brain [156]. The heavy metal cadmium, in cigarette smoke, decreases the bioavailability of selenium (Se) and zinc ( $\mathrm{Zn}$ ) and thus depletes the antioxidant status [157]. The role of BA as chelator of transition metal, inhibition of free radicals, and termination of lipid peroxidation at the initiation level itself [69] accounts for its protection in cigarette smoke induced lipid peroxidative damage and combative against oxidative damage.

8.5. Mitochondrial Functions. Mitochondria are the site of cellular oxidation and provide ATP for various metabolic processes and hence are vulnerable to free radical attack. Mitochondrial damage is prevalent in both heart and brain following cigarette smoke exposure $[158,159]$. Exposure to cigarettes can lead to mitochondrial dysfunction as demonstrated by increased levels of cholesterol, lipid peroxides, and increased cholesterol/phospholipid ratio, in conjunction with decreased mitochondrial enzymes in rats exposed to cigarette smoke [160]. Chronic cigarette smoking prevented exerciseinduced improvement in brain mitochondrial function and neurotransmission [161]. Perturbed mitochondrial energetics is critical in normal brain development $[6,162]$. Cerebellar perturbation can broadly impact regulation of behavioral and cognitive domains [163].

Aerobic demands increase postnatally with heighted synaptic development, requiring more ATP to maintain membrane polarity. Exposure to cigarette smoke perturbed the mitochondria and associated aerobic pathways. The effect of BA in regulating the key aerobic ATP production, probably by preventing the peroxidative changes in mitochondria, could be crucial in mitochondrial mediated neurotransmission pathways. Brain energetics is highly regulated process and further studies in the mechanistics can provide an insight into the role of BA.

8.6. Membrane Integrity and Electrolyte Balance. Derangement of membrane bound enzymes and modifications of lipid bilayer alterations following cigarette smoke exposure 
TABle 3: Activities of ornithine decarboxylase in brain of control and experimental animals. Values are expressed as Mean \pm S.D.

\begin{tabular}{lcccc}
\hline Parameter & Control & $\begin{array}{c}\text { Cigarette smoke } \\
(\mathrm{CS})\end{array}$ & $\begin{array}{c}\text { Bacoside A } \\
(\mathrm{BA})\end{array}$ & $\begin{array}{c}\text { Cigarette smoke + bacoside A } \\
(\mathrm{CS}+\mathrm{BA})\end{array}$ \\
\hline $\begin{array}{l}\text { Ornithine decarboxylase } \\
\text { nM of }{ }^{14} \mathrm{CO}_{2} \text { released/hr/g } \\
\text { tissue }\end{array}$ & $2.0 \pm 0.12$ & $5.65 \pm 0.52$ & $2.23 \pm 0.22$ & $2.45 \pm 0.023^{*}$ \\
\hline
\end{tabular}

Significance is indicated for comparisons between control and CS and BA; Group CS versus CS + BA with Dunnett's T3 post hoc multiple comparison test; ${ }^{*} P<0.001$.

n.d: not detected.

resulted in significant decrease in the activities of ATPases [164]. Free radicals in cigarette smoke deplete cell protein sulfhydryl groups and increase in protein carbonyl formation [165] and so does acetaldehyde in cigarette smoke [166]. Membrane bound ATPases are thiol-dependent enzymes, and modification of thiol groups within the active sites of these enzymes lowers their activities in cigarette smoke rats. The antioxidant role of BA prevented the membrane damage and restored the activities of ATPases. Also the restitution of ATP levels by altering the mitochondrial dysfunction maintained the activities of ATPases.

Inhibition of $\mathrm{Na}^{+} / \mathrm{K}^{+}$-ATPase and elevation of $\mathrm{Na}^{+}$in chronic exposure to cigarette smoke are attributed to the increased cholesterol/phospholipid ratio [167] followed by neuronal apoptotic death mediated by intracellular depletion of $\mathrm{K}^{+}$and accumulation of $\mathrm{Na}^{+}$and $\mathrm{Ca}^{2+}$ [168]. Plasma membrane $\mathrm{Ca}^{2+}$-ATPase (PMCA) is a regulator of intracellular calcium which undergoes early developmental changes in rat brain as a function of its maturity [169]. PMCA is very sensitive to the inhibitory effect of reactive oxygen species (ROS) due to the age dependent oxidative modification of PMCA and the related chronic oxidative stress [170].

In addition to generation of free radicals, cellular degeneration that is involved in cigarette smoking is related to the accumulation of advanced glycosylation end-products (AGE). Activities of several enzymes are inhibited due to enzyme protein glycation $[171,172]$. The changes in the $\mathrm{Ca}^{2+}$ ATPase can be related to the increased glycation found in cigarette smoke exposed rats that in turn may lead to the enzyme protein glycation [173]. Alterations in the capacity to maintain normal calcium homeostasis underlies the reduced cellular function bound with the aging process. In the brain, multiple methionines within the calmodulin molecule become oxidized to methionine sulfoxides, resulting in an inability to activate a range of target proteins, including plasma membrane $\mathrm{Ca}^{2+}$-ATPase [174].

$\mathrm{Mg}^{2+}$-ATPase is not uniformly distributed and differs in respect to affinity for ATP in rat brain regions [175] and is activated by millimolar concentrations of $\mathrm{Mg}^{2+}$. Comparison of $\mathrm{Na}^{+}, \mathrm{K}^{+}$-ATPase, and $\mathrm{Mg}^{2+}$-ATPase activities in the synaptic plasma membrane from various regions of rat brain reveals that moderate hypoxia increases the activity of synaptosomal $\mathrm{Mg}^{2+}$-ATPase whereas activities of both $\mathrm{Ca}^{2+}$ - ATPase and $\mathrm{Na}^{+}, \mathrm{K}^{+}$-ATPase are decreased [176].

Increased concentrations of $\mathrm{Ca}^{2+}$ by stimulating $\mathrm{Na}^{+} / \mathrm{Ca}^{2+}$ exchanger produce cellular $\mathrm{Mg}^{2+}$ depletion since excessive calcium displaces magnesium from its binding sites [177]. Decrease in $\mathrm{Mg}^{2+}$ in turn inhibits $\mathrm{Na}^{+} / \mathrm{K}^{+}$ATPase further, as ATP-Mg complex is the actual substrate for the enzyme [178]. Rats exposed to cigarette smoke showed a decrease in the activity of brain $\mathrm{Mg}^{2+}$-ATPase. The restoration of membrane bound ATPases maintained the electrolyte homeostasis in brain, impairing electrolyte balance in cigarette smoking.

8.7. Apoptotic and Neurogenic Changes. Dysregulation of apoptosis is an important factor in the pathogenesis of cigarette smoking [179]. Nicotine is involved in both stimulation and inhibition of neuronal apoptosis [180-182]. Apoptosis is suggested as a possible contributing factor in the pathogenesis of smoking-induced toxicity. Exposure to cigarette smoke induced apoptosis as characterized by DNA laddering, increased TUNEL-positive cells, and apoptotic features evident ultrasctructurally in the brain. Administration of BA prevented expression of hsp70 and neuronal apoptosis during cigarette smoking [183]. Extract of BM reduced oxidative stress by improving Nrf2 expression and results in improvement in antiapoptotic (Bcl2) expression and decreased proapoptotic (Bax and caspase-3 activity) indicating neuroprotection [184].

8.8. Therapeutic Implications of BA in Passive Smoking. An insight into these observations supports the role of BA as a supplement for secondhand smoking. Its role on $\mathrm{nAChR}$ expression may underpin its effect on cigarettes induced neurochemical alteration. Generally antidepressants are noncompetitive inhibitors of nAChRs [185] and so it is possible that the role of $\mathrm{BA}$ as a noncompetitive inhibitor to nAChRs could potentially help in controlling the nAChR mediated upregulation of neurotransmitters and nicotine dependence [186], apart from its role on $\mathrm{nAChR}$ expression at the transcriptional level.

Other potential sites of action for BA worthy for consideration include its ability to control inflammation and oxidative stress. Antioxidants and anti-inflammatory drugs potentially negate the anxiolytic behaviors $[187,188]$, a feature also prevalent in passive smokers. Exploitation of the antioxidant property of BA could aid in overcoming oxidative anxiety disorders.

\section{Conclusion}

A number of admonitions exist in the data presented. The interpretations are drawn from a study involving chronic 
exposure of rats to cigarette smoke and not acute cigarette smoke. The cross-sectional nature of this work is hampered from conclusions not drawn from molecular pathways. Future research efforts in this area should attempt to address these shortcomings. It would be useful to ascertain the effects of BA on individual components of cigarette smoke constituents involving multiple pathways. Given that passive smoking affects multiple pathways and may increase risk of developing anxiety, triangulation of potential effects involving a combination of animal and human models will likely be required. As the role of $\mathrm{BA}$ appears to be multifaceted, it may represent a future therapeutic means for secondary smoke. In addition, to its neuroactive role, BA as an anti-inflammatory and antioxidant agent may assist in improving the symptoms, as they may do in other conditions pertaining to oxidative stress. Further studies addressing this area may elicit insights into new therapeutic opportunities.

\section{Conflict of Interests}

The authors declare that there is no conflict of interests regarding the publication of this paper.

\section{Acknowledgment}

This work was supported by the Council for Scientific and Industrial Research, New Delhi.

\section{References}

[1] World Health Organization, "Warning about the dangers of tobacco," WHO Report on the Global Tobacco Epidemic, 2011.

[2] California Environmental Protection Agency, Proposed Identification of Environmental Tobacco Smoke as a Toxic Air Contaminant, 2005, http://repositories.cdlib.org/tc/surveys/ CALEPA2005.

[3] L. Anderko, J. Braun, and P. Auinger, "Contribution of tobacco smoke exposure to learning disabilities," Journal of Obstetric, Gynecologic, and Neonatal Nursing, vol. 39, no. 1, pp. 111-117, 2010.

[4] F. C. Bandiera, A. Kalaydjian Richardson, D. J. Lee, J.-P. He, and K. R. Merikangas, "Secondhand smoke exposure and mental health among children and adolescents," Archives of Pediatrics and Adolescent Medicine, vol. 165, no. 4, pp. 332-338, 2011.

[5] Z. Kabir, G. N. Connolly, and H. R. Alpert, "Secondhand smoke exposure and neurobehavioral disorders among children in the United States," Pediatrics, vol. 128, no. 2, pp. 263-270, 2011.

[6] S. P. Doherty, J. Grabowski, C. Hoffman, S. P. Ng, and J. T. Zelikoff, "Early life insult from cigarette smoke may be predictive of chronic diseases later in life," Biomarkers, vol. 14, supplement 1, pp. 97-101, 2009.

[7] J. R. Pauly and T. A. Slotkin, "Maternal tobacco smoking, nicotine replacement and neurobehavioural development," Acta Paediatrica, International Journal of Paediatrics, vol. 97, no. 10, pp. 1331-1337, 2008.

[8] M. Berk, F. Kapczinski, A. C. Andreazza et al., "Pathways underlying neuroprogression in bipolar disorder: focus on inflammation, oxidative stress and neurotrophic factors," $\mathrm{Neu}$ roscience and Biobehavioral Reviews, vol. 35, no. 3, pp. 804-817, 2011.
[9] S. Moylan, M. Maes, N. R. Wray, and M. Berk, "The neuroprogressive nature of major depressive disorder: pathways to disease evolution and resistance, and therapeutic implications," Molecular Psychiatry, vol. 18, no. 5, pp. 595-606, 2013.

[10] K. J. Ameringer and A. M. Leventhal, "Applying the tripartite model of anxiety and depression to cigarette smoking: an integrative review," Nicotine and Tobacco Research, vol. 12, no. 12, pp. 1183-1194, 2010.

[11] O. N. Niedermaier, M. L. Smith, L. A. Beightol, Z. ZukowskaGrojec, D. S. Goldstein, and D. L. Eckberg, "Influence of cigarette smoking on human autonomic function," Circulation, vol. 88, no. 2, pp. 562-571, 1993.

[12] W. A. Pryor, K. Stone, C. E. Cross, L. Machlin, and L. Packer, "Oxidants in cigarette smoke: radicals, hydrogen peroxide, peroxynitrate, and peroxynitrite," Annals of the New York Academy of Sciences, vol. 686, pp. 12-28, 1993.

[13] C. J. Smith and T. H. Fischer, "Particulate and vapor phase constituents of cigarette mainstream smoke and risk of myocardial infarction," Atherosclerosis, vol. 158, no. 2, pp. 257-267, 2001.

[14] W. A. Pryor, K. Stone, L.-Y. Zang, and E. Bermudez, "Fractionation of aqueous cigarette tar extracts: fractions that contain the tar radical cause DNA damage," Chemical Research in Toxicology, vol. 11, no. 5, pp. 441-448, 1998.

[15] A. E. Taylor, D. C. Johnson, and H. Kazemi, "Environmental tobacco smoke and cardiovascular disease: a position paper from the council on cardiopulmonary and critical care, American Heart Association," Circulation, vol. 86, no. 2, pp. 699-702, 1992.

[16] J. E. Harris, "Cigarette smoke components and disease: cigarette smoke is morethan a triad of tar, nicotine, and carbon monoxide," http://cancercontrol.cancer.gov/brp/TCRB/monographs/ 7/m7_5.

[17] J. D. Adams, K. J. O’Mara-Adams, and D. Hoffmann, “Toxic and carcinogenic agents in undiluted mainstream smoke and sidestream smoke of different types of cigarettes," Carcinogenesis, vol. 8, no. 5, pp. 729-731, 1987.

[18] M. S. Jaakkola and J. J. K. Jaakkola, "Assessment of exposure to environmental tobacco smoke," European Respiratory Journal, vol. 10, no. 10, pp. 2384-2397, 1997.

[19] L. T. Kozlowski, N. Y. Mehta, C. T. Sweeney et al., "Filter ventilation and nicotine content of tobacco in cigarettes from Canada, the United Kingdom, and the United States," Tobacco Control, vol. 7, no. 4, pp. 369-375, 1998.

[20] A. K. Armitage, C. T. Dollery, C. F. George, T. H. Houseman, P. J. Lewis, and D. M. Turner, "Absorption and metabolism of nicotine from cigarettes," British Medical Journal, vol. 4, no. 5992, pp. 313-316, 1975.

[21] A. Cohen and O. George, "Animal models of nicotine exposure: relevance to second-hand smoking, electronic cigarette use, and compulsive smoking," Frontiers in Psychiatry, vol. 4, article 41, 2013.

[22] M. R. Picciotto, M. Zoli, R. Rimondini et al., "Acetylcholine receptors containing the beta2 subunit are involved in the reinforcing properties of nicotine," Nature, vol. 391, no. 6663, pp. 173-177, 1998.

[23] N. L. Benowitz, "Pharmacology of nicotine: addiction, smoking-induced disease, and therapeutics," Annual Review of Pharmacology and Toxicology, vol. 49, pp. 57-71, 2009.

[24] A. L. Brody, "Functional brain imaging of tobacco use and dependence," Journal of Psychiatric Research, vol. 40, no. 5, pp. 404-418, 2006. 
[25] U.S. Department of Health and Human Services, The Health Consequences of Smoking: Nicotine Addiction, A Report of the Surgeon General No. DHHS Publication No. 88-8406, Centers for Disease Control, Office of Smoking and Health, Public Health Service, Rockville, Md, USA, 1988.

[26] I. P. Stolerman and M. J. Jarvis, "The scientific case that nicotine is addictive," Psychopharmacology, vol. 117, no. 1, pp. 2-10, 1995.

[27] T. J. Abbruscato, S. P. Lopez, K. S. Mark, B. T. Hawkins, and T. P. Davis, "Nicotine and cotinine modulate cerebral microvascular permeability and protein expression of ZO-1 through nicotinic acetylcholine receptors expressed on brain endothelial cells," Journal of Pharmaceutical Sciences, vol. 91, no. 12, pp. 2525-2538, 2002.

[28] J. R. Paulson, K. E. Roder, G. McAfee, D. D. Allen, C. J. Van Der Schyf, and T. J. Abbruscato, "Tobacco smoke chemicals attenuate brain-to-blood potassium transport mediated by the $\mathrm{Na}, \mathrm{K}, 2 \mathrm{Cl}$-cotransporter during hypoxia-reoxygenation," Journal of Pharmacology and Experimental Therapeutics, vol. 316, no. 1, pp. 248-254, 2006.

[29] D. Bernhard, C. Moser, A. Backovic, and G. Wick, "Cigarette smoke-an aging accelerator?” Experimental Gerontology, vol. 42, no. 3, pp. 160-165, 2007.

[30] J. A. Sonnen, E. B. Larson, S. L. Gray et al., "Free radical damage to cerebral cortex in alzheimer's disease, microvascular brain injury, and smoking," Annals of Neurology, vol. 65, no. 2, pp. 226-229, 2009.

[31] P. Mazzone, W. Tierney, M. Hossain, V. Puvenna, D. Janigro, and L. Cucullo, "Pathophysiological impact of cigarette smoke exposure on the cerebrovascular system with a focus on the blood-brain barrier: expanding the awareness of smoking toxicity in an underappreciated area," International Journal of Environmental Research and Public Health, vol. 7, no. 12, pp. 4111-4126, 2010.

[32] G. J. Hankey, "Smoking and risk of stroke," Journal of Cardiovascular Risk, vol. 6, no. 4, pp. 207-211, 1999.

[33] I. C. Manchev, P. P. Mineva, and D. I. Hadjiev, "Prevalence of stroke risk factors and their outcomes: a population-based longitudinal epidemiological study," Cerebrovascular Diseases, vol. 12, no. 4, pp. 303-307, 2001.

[34] J. S. Gill, M. J. Shipley, S. A. Tsementzis et al., "Cigarette smoking. A risk factor for hemorrhagic and nonhemorrhagic stroke," Archives of Internal Medicine, vol. 149, no. 9, pp. 20532057, 1989.

[35] P. Decina, G. Caracci, R. Sandik, W. Berman, S. Mukherjee, and P. Scapicchio, "Cigarette smoking and neuroleptic-induced parkinsonism," Biological Psychiatry, vol. 28, no. 6, pp. 502-508, 1990.

[36] J. A. Johnsen and V. T. Miller, "Tobacco intolerance on multiple system atrophy," Neurology, vol. 36, no. 7, pp. 986-988, 1986.

[37] G. D. Mellick, “CYP450, genetics and Parkinson's disease: Gene $\mathrm{x}$ environment interactions hold the key," Journal of Neural Transmission. Supplementum, no. 70, pp. 159-165, 2006.

[38] J. R. Barrett, "Dementia and secondhand smoke," Environmental Health Perspectives, vol. 115, article A401, 2007.

[39] R. Peters, R. Poulter, J. Warner, N. Beckett, L. Burch, and C. Bulpitt, "Smoking, dementia and cognitive decline in the elderly, a systematic review," BMC Geriatrics, vol. 8 , article 36 , 2008.

[40] J. T. Powell, "Vascular damage from smoking: disease mechanisms at the arterial wall," Vascular Medicine, vol. 3, no. 1, pp. 21-28, 1998.
[41] D. E. Barnes, T. J. Haight, K. M. Mehta, M. C. Carlson, L. H. Kuller, and I. B. Tager, "Secondhand smoke, vascular disease, and dementia incidence: findings from the cardiovascular health cognition study," American Journal of Epidemiology, vol. 171, no. 3, pp. 292-302, 2010.

[42] D. J. Llewellyn, L. A. Lang, K. M. Langa, F. Naughton, and F. E. Matthews, "Exposure to secondhand smoke and cognitive impairment in non-smokers: national cross sectional study with cotinine measurement," British Medical Journal, vol. 338, article b462, 2009.

[43] M. N. Sabbagh, S. L. Tyas, S. C. Emery et al., "Smoking affects the phenotype of Alzheimer disease," Neurology, vol. 64, no. 7, pp. 1301-1303, 2005.

[44] A. L. Brody, M. A. Mandelkern, E. D. London et al., "Cigarette smoking saturates brain $\alpha_{4} \beta_{2}$ nicotinic acetylcholine receptors," Archives of General Psychiatry, vol. 63, no. 8, pp. 907-915, 2006.

[45] A. L. Brody, M. A. Mandelkern, E. D. London et al., "Effect of second hand smoke on occupancy of nicotinic acetylcholine receptors in brain," Archives of General Psychiatry, vol. 68, no. 9, pp. 953-960, 2011.

[46] US Public Health Service and Office of the Surgeon General, The Health Consequences of Involuntary Exposure to Tobacco Smoke: A Report of the Surgeon General, US Department of Health and Human Services, Public Health Service, Office of the Surgeon General, Rockville, Md, USA, 2006.

[47] M. J. Jarvis, P. Hajek, M. A. H. Russell, R. J. West, and C. Feyerabend, "Nasal nicotine solution as an aid to cigarette withdrawal: a pilot clinical trial," The British Journal of Addiction, vol. 82, no. 9, pp. 983-988, 1987.

[48] W. Lam, H. S. Sacks, P. Sze, and T. C. Chalmers, "Meta-analysis of randomised controlled trials of nicotine chewing-gum," The Lancet, vol. 2, no. 8549, pp. 27-30, 1987.

[49] P. Tønnesen, J. Nørregaard, K. Simonsen, and U. Säwe, “A double-blind trial of a 16-hour transdermal nicotine patch in smoking cessation," The New England Journal of Medicine, vol. 325, no. 5, pp. 311-315, 1991.

[50] H. El-Bizri and P. B. S. Clarke, "Blockade of nicotinic receptormediated release of dopamine from striatal synaptosomes by chlorisondamine and other nicotinic antagonists administered in vitro," British Journal of Pharmacology, vol. 111, no. 2, pp. 406413, 1994.

[51] M. J. Tobin, G. Jenouri, and M. A. Sackner, "Effect of naloxone on change in breathing pattern with smoking. A hypothesis on the addictive nature of cigarette smoking," Chest, vol. 82, no. 5, pp. 530-537, 1982.

[52] I. P. Stolerman, T. Goldfarb, R. Fink, and M. E. Jarvik, "Influencing cigarette smoking with nicotine antagonists," Psychopharmacologia, vol. 28, no. 3, pp. 247-259, 1973.

[53] I. Berlin, S. Saïd, O. Spreux-Varoquaux et al., "A reversible monoamine oxidase a inhibitor (moclobemide) facilitates smoking cessation and abstinence in heavy, dependent smokers," Clinical Pharmacology and Therapeutics, vol. 58, no. 4, pp. 444-452, 1995.

[54] N. B. Edwards, J. K. Murphy, A. D. Downs, B. J. Ackerman, and T. L. Rosenthal, "Doxepin as an adjunct to smoking cessation: a double-blind pilot study," The American Journal of Psychiatry, vol. 146, no. 3, pp. 373-376, 1989.

[55] F. Gawin, M. Compton, and R. Byck, "Buspirone reduces smoking," Archives of General Psychiatry, vol. 46, no. 3, pp. 288$289,1989$. 
[56] V. Nicita-Mauro, "Smoking, calcium, calcium antagonists, and aging," Experimental Gerontology, vol. 25, no. 3-4, pp. 393-399, 1990.

[57] P. Pentel and D. Malin, "A vaccine for nicotine dependence: targeting the drug rather than the brain," Respiration, vol. 69, no. 3, pp. 193-197, 2002.

[58] J. A. Ascher, J. O. Cole, J.-N. Colin et al., "Bupropion: a review of its mechanism of antidepressant activity," Journal of Clinical Psychiatry, vol. 56, no. 7, pp. 395-401, 1995.

[59] M. I. Damaj, F. I. Carroll, J. B. Eaton et al., "Enantioselective effects of hydroxy metabolites of bupropion on behavior and on function of monoamine transporters and nicotinic receptors," Molecular Pharmacology, vol. 66, no. 3, pp. 675-682, 2004.

[60] J. W. Coe, P. R. Brooks, M. G. Vetelino et al., "Varenicline: an alpha4beta2 nicotinic receptor partial agonist for smoking cessation," Journal of Medicinal Chemistry, vol. 48, no. 10, pp. 3474-3477, 2005.

[61] A. Helen and P. L. Vijayammal, "Effect of vitamin A supplementation on cigarette smoke-induced lipid peroxidation," Veterinary and Human Toxicology, vol. 39, no. 1, pp. 18-21, 1997.

[62] N. Dilsiz, A. Olcucu, M. Cay, M. Naziroglu, and D. Cabanoglu, "Protective effects of selenium, vitamin C and vitamin E against oxidative stress of cigarette smoke in rats," Cell Biochemistry and Function, vol. 17, no. 1, pp. 1-7, 1999.

[63] A. Izzotti, R. M. Balansky, F. D’Agostini et al., "Modulation of biomarkers by chemopreventive agents in smoke-exposed rats," Cancer Research, vol. 61, no. 6, pp. 2472-2479, 2001.

[64] S. Chitra, R. Semmalar, and C. S. S. Devi, "Effect of fish oil on cigarette smoking induced dyslipidemia in rats," Indian Journal of Pharmacology, vol. 32, no. 2, pp. 114-119, 2000.

[65] S. Shishodia, P. Potdar, C. G. Gairola, and B. B. Aggarwal, "Curcumin (diferuloylmethane) down-regulates cigarette smokeinduced NF- $\kappa \mathrm{B}$ activation through inhibition of $\mathrm{I} \kappa \mathrm{B} \alpha$ kinase in human lung epithelial cells: correlation with suppression of COX-2, MMP-9 and cyclin D1," Carcinogenesis, vol. 24, no. 7, pp. 1269-1279, 2003.

[66] J. S. Shim, M. H. Kang, Y. H. Kim, J. K. Roh, C. Roberts, and I. P. Lee, "Chemopreventive effect of green tea (Camellia sinensis) among cigarette smokers," Cancer Epidemiology Biomarkers and Prevention, vol. 4, no. 4, pp. 387-391, 1995.

[67] S. Roodenrys, D. Booth, S. Bulzomi, A. Phipps, C. Micallef, and J. Smoker, "Chronic effects of Brahmi (Bacopa monnieri) on human memory," Neuropsychopharmacology, vol. 27, no. 2, pp. 279-281, 2002.

[68] T. Murugesan, "Evaluation of psychopharmacological effects of Bacopa monnieri Linn Extract," Phytomedicine, vol. 8, pp. 472476, 2005.

[69] Y. B. Tripathi, S. Chaurasia, E. Tripathi, A. Upadhyay, and G. P. Dubey, "Bacopa monniera Linn. as an antioxidant: mechanism of action," Indian Journal of Experimental Biology, vol. 34, no. 6, pp. 523-526, 1996.

[70] S. Channa, A. Dar, M. Yaqoob, S. Anjum, Z. Sultani, and A.U. Rahman, "Broncho-vasodilatory activity of fractions and pure constituents isolated from Bacopa monniera," Journal of Ethnopharmacology, vol. 86, no. 1, pp. 27-35, 2003.

[71] A. Dar and S. Channa, "Calcium antagonistic activity of Bacopa monniera on vascular and intestinal smooth muscles of rabbit and guinea-pig," Journal of Ethnopharmacology, vol. 66, no. 2, pp. 167-174, 1999.

[72] D. S. Samiulla, D. Prashanth, and A. Amit, "Mast cell stabilising activity of Bacopa monnieri," Fitoterapia, vol. 72, no. 3, pp. 284285, 2001.
[73] H. K. Singh, "Memory-enhancing and associated effects of a bacosides enriched standardised extract of Bacopa monniera," in Advances in Natural Medicines, Nutraceuticals and Neurocognition, C. Stough and A. Scholey, Eds., pp. 251-288, CRC Press, Taylor \& Francis, London, UK, 2013.

[74] S. Majumdar, A. Basu, P. Paul, M. Halder, and S. Jha, "Bacosides and Neuroprotection," in Natural Products: Phytochemistry, Botany and Metabolism of Alkaloids, Phenolics and Terpenes, $\mathrm{K}$. Ramawat and J. Merillon, Eds., pp. 3639-3660, Springer, Berlin, Germany, 2013.

[75] S. Garai, S. B. Mahato, K. Ohtani, and K. Yamasaki, "Dammarane-type triterpenoid saponins from Bacopa monniera," Phytochemistry, vol. 42, no. 3, pp. 815-820, 1996.

[76] A. K. Chakravarty, T. Sarkar, T. Nakane, N. Kawahara, K. Masuda, and K. Shiojima, "Bacopaside I and II: two pseudojujubogenin glycosides from Bacopa monniera," Phytochemistry, vol. 58, no. 4, pp. 553-556, 2001.

[77] A. K. Chakravarty, T. Sarkar, T. Nakane, N. Kawahara, and K. Masuda, "New phenylethanoid glycosides from Bacopa monniera," Chemical and Pharmaceutical Bulletin, vol. 50, no. 12, pp. 1616-1618, 2002.

[78] A. K. Chakravarty, S. Garai, K. Masuda, T. Nakane, and N. Kawahara, "Bacopasides III-V: three new triterpenoid glycosides from Bacopa monniera," Chemical and Pharmaceutical Bulletin, vol. 51, no. 2, pp. 215-217, 2003.

[79] K. Anbarasi, G. Vani, K. Balakrishna, and C. S. S. Devi, "Creatine kinase isoenzyme patterns upon chronic exposure to cigarette smoke: protective effect of Bacoside A," Vascular Pharmacology, vol. 42, no. 2, pp. 57-61, 2005.

[80] E. Madhukumar and P. L. Vijayammal, "Influence of cigarette smoke on cross-linking of dermal collagen," Indian Journal of Experimental Biology, vol. 35, no. 5, pp. 483-486, 1997.

[81] World Health Organization, WHO Report on the Global Tobacco Epidemic 2011. Warning about the Dangers of Tobacco, World Health Organization, Geneva, Switzerland, 2011.

[82] R. A. R. Gons, A. G. W. van Norden, K. F. de Laat et al., "Cigarette smoking is associated with reduced microstructural integrity of cerebral white matter," Brain, vol. 134, no. 7, pp. 21162124, 2011.

[83] A. L. Brody, M. A. Mandelkern, M. E. Jarvik et al., "Differences between smokers and nonsmokers in regional gray matter volumes and densities," Biological Psychiatry, vol. 55, no. 1, pp. 77-84, 2004.

[84] X. Zhang, E. A. Stein, and L. E. Hong, "Smoking and schizophrenia independently and additively reduce white matter integrity between striatum and frontal cortex," Biological Psychiatry, vol. 68, no. 7, pp. 674-677, 2010.

[85] T. C. Durazzo, D. J. Meyerhoff, and S. J. Nixon, "Chronic cigarette smoking: implications for neurocognition and brain neurobiology," International Journal of Environmental Research and Public Health, vol. 7, no. 10, pp. 3760-3790, 2010.

[86] R. H. Paul, S. M. Grieve, R. Niaura et al., "Chronic cigarette smoking and the microstructural integrity of white matter in healthy adults: a diffusion tensor imaging study," Nicotine and Tobacco Research, vol. 10, no. 1, pp. 137-147, 2008.

[87] R. A. Wevers, P. H. P. Jansen, L. M. J. van Woerkom, W. H. Doesburg, and O. R. Hommes, "The significance of total creatine kinase activity and isozyme determinations in cerebrospinal fluid of neurological patients," Clinica Chimica Acta, vol. 143, no. 3, pp. 193-201, 1984. 
[88] S. V. Bhagwat, C. Vijayasarathy, H. Raza, J. Mullick, and N. G. Avadhani, "Preferential effects of nicotine and 4-(N-methyl-Nnitrosamine)-1-(3-pyridyl)-1-butanone on mitochondrial glutathione S-transferase A4-4 induction and increased oxidative stress in the rat brain," Biochemical Pharmacology, vol. 56, no. 7, pp. 831-839, 1998.

[89] Z. Jin, F. Gao, T. Flagg, and X. Deng, "Tobacco-specific nitrosamine 4-(methylnitrosamino)-1-(3-pyridyl)-1-butanone promotes functional cooperation of $\mathrm{Bcl} 2$ and c-Myc through phosphorylation in regulating cell survival and proliferation," The Journal of Biological Chemistry, vol. 279, no. 38, pp. 40209-40219, 2004.

[90] W. S. Griffin, "Inflammation and neurodegenerative diseases," The American Journal of Clinical Nutrition, vol. 83, pp. 470S474S, 2006.

[91] V. Viji and A. Helen, "Inhibition of pro-inflammatory mediators: role of Bacopa monniera (L.) Wettst," Inflammopharmacology, vol. 19, no. 5, pp. 283-291, 2011.

[92] V. J. Knott, "Electroencephalographic characterization of cigarette smoking behavior," Alcohol, vol. 24, no. 2, pp. 95-97, 2001.

[93] H. Shikata, H. Fukai, I. Ohya, and T. Sakaki, "Characterization of topographic EEG changes when smoking a cigarette," Psychopharmacology, vol. 119, no. 4, pp. 361-367, 1995.

[94] B. B. Brown, "Frequency and phase of hippocampal theta activity in the spontaneously behaving cat," Electroencephalography and Clinical Neurophysiology, vol. 24, no. 1, pp. 53-62, 1968.

[95] E. J. Nestler, "Molecular mechanisms of drug addiction," Journal of Neuroscience, vol. 12, no. 7, pp. 2439-2450, 1992.

[96] D. Bertrand, "Neurocircuitry of the nicotinic cholinergic system," Dialogues in Clinical Neuroscience, vol. 12, no. 4, pp. 463470, 2010.

[97] K. L. Summers and E. Giacobini, "Effects of local and repeated systemic administration of (-)nicotine on extracellular levels of acetylcholine, norepinephrine, dopamine, and serotonin in rat cortex," Neurochemical Research, vol. 20, no. 6, pp. 753-759, 1995.

[98] M. J. Marks, T. D. McClure-Begley, P. Whiteaker et al., "Increased nicotinic acetylcholine receptor protein underlies chronic nicotine-induced up-regulation of nicotinic agonist binding sites in mouse brain," Journal of Pharmacology and Experimental Therapeutics, vol. 337, no. 1, pp. 187-200, 2011.

[99] X. Zhang, J.-Y. Tian, A.-L. Svensson, Z.-H. Gong, B. Meyerson, and A. Nordberg, "Chronic treatments with tacrine and (-)nicotine induce different changes of nicotinic and muscarinic acetylcholine receptors in the brain of aged rat," Journal of Neural Transmission, vol. 109, no. 3, pp. 377-392, 2002.

[100] P. J. Whiting and J. M. Lindstrom, "Characterization of bovine and human neuronal nicotinic acetylcholine receptors using monoclonal antibodies," Journal of Neuroscience, vol. 8, no. 9, pp. 3395-3404, 1988.

[101] M. Mamede, K. Ishizu, M. Ueda et al., "Temporal change in human nicotinic acetylcholine receptor after smoking cessation: 5IA SPECT study," Journal of Nuclear Medicine, vol. 48, no. 11, pp. 1829-1835, 2007.

[102] K. P. Cosgrove, I. Esterlis, S. A. McKee et al., "Sex differences in availability of $\beta 2^{*}$-nicotinic acetylcholine receptors in recently abstinent tobacco smokers," Archives of General Psychiatry, vol. 69, no. 4, pp. 418-427, 2012.

[103] A. P. Govind, P. Vezina, and W. N. Green, "Nicotine-induced upregulation of nicotinic receptors: underlying mechanisms and relevance to nicotine addiction," Biochemical Pharmacology, vol. 78, no. 7, pp. 756-765, 2009.

[104] A. W. Bergen, H. S. Javitz, R. Krasnow et al., "Nicotinic acetylcholine receptor variation and response to smoking cessation therapies," Pharmacogenetics and Genomics, vol. 23, no. 2, pp. 94-103, 2013.

[105] W. B. Pickworth, R. M. Keenan, and J. E. Henningfield, "Nicotine: effects and mechanism," in Handbook of Neurotoxicology, L. W. Chang and R. S. Dyer, Eds., pp. 808-818, Marcel Dekker, New York, NY, USA, 1995.

[106] A. K. Armitage and G. H. Hall, "Mode of action of intravenous nicotine in causing a fall of blood pressure in the cat," European Journal of Pharmacology, vol. 7, no. 1, pp. 23-30, 1969.

[107] A. J. Dunn and S. C. Bondy, Functional Chemistry of the Brain, Spectrum Publications, Halsted Press, New York, NY, USA, 1974.

[108] J. Mathew, J. Paul, M. S. Nandhu, and C. S. Paulose, "Increased excitability and metabolism in pilocarpine induced epileptic rats: effect of Bacopa monnieri," Fitoterapia, vol. 81, no. 6, pp. 546-551, 2010.

[109] J. H. Markovitz, L. Tolbert, and S. E. Winders, "Increased serotonin receptor density and platelet GPIIb/IIIa activation among smokers," Arteriosclerosis, Thrombosis, and Vascular Biology, vol. 19, no. 3, pp. 762-766, 1999.

[110] S. N. Mitchell, K. M. Smith, M. H. Joseph, and J. A. Gray, "Increases in tyrosine hydroxylase messenger RNA in the locus coeruleus after a single dose of nicotine are followed by timedependent increases in enzyme activity and noradrenaline release," Neuroscience, vol. 56, no. 4, pp. 989-997, 1993.

[111] W. G. Mayhan, "Acute infusion of nicotine potentiates norepinephrine-induced vasoconstriction in the hamster cheek pouch," Journal of Laboratory and Clinical Medicine, vol. 133, no. 1, pp. 48-54, 1999.

[112] D. M. Rajathei, J. Preethi, H. K. Singh, and K. E. Rajan, "Molecular docking of bacosides with tryptophan hydroxylase: a model to understand the bacosides mechanism," Natural Products and Bioprospecting, vol. 4, no. 4, pp. 251-255, 2014.

[113] E. B. Ribeiro, R. L. Bettiker, M. Bogdanov, and R. J. Wurtman, "Effects of systemic nicotine on serotonin release in rat brain," Brain Research, vol. 621, no. 2, pp. 311-318, 1993.

[114] M. Reuben and P. B. S. Clarke, "Nicotine-evoked $\left[{ }^{3} \mathrm{H}\right]$ 5hydroxytryptamine release from rat striatal synaptosomes," Neuropharmacology, vol. 39, no. 2, pp. 290-299, 2000.

[115] M. E. M. Benwell, D. J. K. Balfour, and J. M. Anderson, "Smoking-associated changes in the serotonergic systems of discrete regions of human brain," Psychopharmacology, vol. 102, no. 1 , pp. 68-72, 1990.

[116] W. Z. Potter and H. K. Manji, "Catecholamines in depression: an update," Clinical Chemistry, vol. 40, no. 2, pp. 279-287, 1994.

[117] R. F. Anda, D. F. Williamson, L. G. Escobedo, E. E. Mast, G. A. Giovino, and P. L. Remington, "Depression and the dynamics of smoking. A national perspective," The Journal of the American Medical Association, vol. 264, no. 12, pp. 1541-1545, 1990.

[118] K. E. Rajan, H. K. Singh, A. Parkavi, and P. D. Charles, "Attenuation of 1-(m-chlorophenyl)-biguanide induced hippocampusdependent memory impairment by a standardised extract of Bacopa monniera (BESEB CDRI-08)," Neurochemical Research, vol. 36, no. 11, pp. 2136-2144, 2011.

[119] T. G. Hastings, D. A. Lewis, and M. J. Zigmond, "Role of oxidation in the neurotoxic effects of intrastriatal dopamine injections," Proceedings of the National Academy of Sciences of the United States of America, vol. 93, no. 5, pp. 1956-1961, 1996. 
[120] N. Sheikh, A. Ahmad, K. B. Siripurapu, V. K. Kuchibhotla, S. Singh, and G. Palit, "Effect of Bacopa monniera on stress induced changes in plasma corticosterone and brain monoamines in rats," Journal of Ethnopharmacology, vol. 111, no. 3, pp. 671-676, 2007.

[121] S. Wonnacott, "Presynaptic nicotinic ACh receptors," Trends in Neurosciences, vol. 20, no. 2, pp. 92-98, 1997.

[122] H. D. Mansvelder and D. S. McGehee, "Cellular and synaptic mechanisms of nicotine addiction," Journal of Neurobiology, vol. 53, no. 4, pp. 606-617, 2002.

[123] A. Lewis, J. H. Miller, and R. A. Lea, "Monoamine oxidase and tobacco dependence," NeuroToxicology, vol. 28, no. 1, pp. 182195, 2007.

[124] A.-S. Villégier, S. Lotfipour, S. C. McQuown, J. D. Belluzzi, and F. M. Leslie, "Tranylcypromine enhancement of nicotine selfadministration," Neuropharmacology, vol. 52, no. 6, pp. 14151425, 2007.

[125] J. S. Fowler, N. D. Volkow, G.-J. Wang et al., "Brain monoamine oxidase A inhibition in cigarette smokers," Proceedings of the National Academy of Sciences of the United States of America, vol. 93, no. 24, pp. 14065-14069, 1996.

[126] J. S. Fowler, N. D. Volkow, G.-J. Wang et al., "Inhibition of monoamine oxidase B in the brains of smokers," Nature, vol. 379, no. 6567, pp. 733-736, 1996.

[127] F. Rendu, K. Peoc'h, I. Berlin, D. Thomas, and J.-M. Launay, "Smoking related diseases: the central role of monoamine oxidase," International Journal of Environmental Research and Public Health, vol. 8, no. 1, pp. 136-147, 2011.

[128] R. Singh, R. Ramakrishna, M. Bhateria, and R. S. Bhatta, "In vitro evaluation of Bacopa monniera extract and individual constituents on human recombinant monoamine oxidase enzymes," Phytotherapy Research, vol. 28, no. 9, pp. 1419-1422, 2014.

[129] C. L. Law, P. C. L. Wong, and W. F. Fong, "Effects of polyamines on the uptake of neurotransmitters by rat brain synaptosomes," Journal of Neurochemistry, vol. 42, no. 3, pp. 870-872, 1984.

[130] T. A. Slotkin, B. D. Freibaum, C. A. Tate et al., "Longlasting CNS effects of a short-term chemical knockout of ornithine decarboxylase during development: nicotinic cholinergic receptor upregulation and subtle macromolecular changes in adulthood," Brain Research, vol. 981, no. 1-2, pp. 118-125, 2003.

[131] L. J. Reed and J. de Belleroche, "Induction of ornithine decarboxylase in cerebral cortex by excitotoxin lesion of nucleus basalis: association with postsynaptic responsiveness and $\mathrm{N}$ methyl-D-aspartate receptor activation," Journal of Neurochemistry, vol. 55, no. 3, pp. 780-787, 1990.

[132] J. A. Lukkarinen, R. A. Kauppinen, O. H. Gröhn et al., "Neuroprotective role of ornithine decarboxylase activation in transient focal cerebral ischaemia: a study using ornithine decarboxylase-overexpressing transgenic rats," European Journal of Neuroscience, vol. 10, no. 6, pp. 2046-2055, 1998.

[133] G. A. Dienel and N. F. Cruz, "Induction of brain ornithine decarboxylase during recovery from metabolic, mechanical, thermal, or chemical injury," Journal of Neurochemistry, vol. 42, no. 4, pp. 1053-1061, 1984.

[134] F. Facchinetti, M. Virgili, P. Migani, O. Barnabei, and A. Contestabile, "Induction of brain ornithine decarboxylase after systemic or intrastriatal administration of kainic acid," Neuroscience Letters, vol. 140, no. 1, pp. 59-62, 1992.

[135] S. Ramasamy, L. V. Kiew, and L. Y. Chung, "Inhibition of human cytochrome P450 enzymes by Bacopa monnieri standardized extract and constituents," Molecules, vol. 19, no. 2, pp. 25882601, 2014.

[136] D. Kar Chowdhuri, D. Parmar, P. Kakkar, R. Shukla, P. K. Seth, and R. C. Srimal, "Antistress effects of bacosides of Bacopa monnieri: modulation of Hsp70 expression, superoxide dismutase and cytochrome $\mathrm{P} 450$ activity in rat brain," Phytotherapy Research, vol. 16, no. 7, pp. 639-645, 2002.

[137] S. Zevin and N. L. Benowitz, "Drug interactions with tobacco smoking. An update," Clinical Pharmacokinetics, vol. 36, no. 6, pp. 425-438, 1999.

[138] N. L. Benowitz and P. Jacob III, "Effects of cigarette smoking and carbon monoxide on nicotine and cotinine metabolism," Clinical Pharmacology and Therapeutics, vol. 67, no. 6, pp. 653659, 2000.

[139] N. L. Benowitz, F. Kuyt, and P. Jacob III, "Circadian blood nicotine concentrations during cigarette smoking," Clinical Pharmacology and Therapeutics, vol. 32, no. 6, pp. 758-764, 1982.

[140] S. Zevin, P. Jacob III, and N. Benowitz, "Cotinine effects on nicotine metabolism," Clinical Pharmacology and Therapeutics, vol. 61, no. 6, pp. 649-654, 1997.

[141] T. T. Denton, X. Zhang, and J. R. Cashman, "Nicotine-related alkaloids and metabolites as inhibitors of human cytochrome P-450 2A6," Biochemical Pharmacology, vol. 67, no. 4, pp. 751$756,2004$.

[142] K. A. Schoedel, E. M. Sellers, R. Palmour, and R. F. Tyndale, "Down-regulation of hepatic nicotine metabolism and a CYP2A6-like enzyme in African green monkeys after long-term nicotine administration," Molecular Pharmacology, vol. 63, no. 1, pp. 96-104, 2003.

[143] H. L. Liston, J. S. Markowitz, and C. L. DeVane, "Drug glucuronidation in clinical psychopharmacology," Journal of Clinical Psychopharmacology, vol. 21, no. 5, pp. 500-515, 2001.

[144] K. Anbarasi, Neuroprotective role of Bacoside A in rats exposed to cigarette smoke [Ph.D. thesis], University of Madras, Chennai, India, 2005.

[145] D. Rai, G. Bhatia, G. Palit, R. Pal, S. Singh, and H. K. Singh, "Adaptogenic effect of Bacopa monniera (Brahmi)," Pharmacology Biochemistry and Behavior, vol. 75, no. 4, pp. 823-830, 2003.

[146] N. Delibas, R. Ozcankaya, I. Altuntas, and R. Sutcu, "Effect of cigarette smoke on lipid peroxidation, antioxidant enzymes and NMDA receptor subunits $2 \mathrm{~A}$ and $2 \mathrm{~B}$ concentration in rat hippocampus," Cell Biochemistry and Function, vol. 21, no. 1, pp. 69-73, 2003.

[147] K. Anbarasi, G. Vani, K. Balakrishna, and C. S. S. Devi, “Effect of bacoside A on brain antioxidant status in cigarette smoke exposed rats," Life Sciences, vol. 78, no. 12, pp. 1378-1384, 2006.

[148] J. Hilbert and V. Mohsenin, "Adaptation of lung antioxidants to cigarette smoking in humans," Chest, vol. 110, no. 4, pp. 916-920, 1996.

[149] S. A. Hulea, R. Olinescu, S. Nita, D. Crocnan, and F. A. Kummerow, "Cigarette smoking causes biochemical changes in blood that are suggestive of oxidative stress: a case-control study," Journal of Environmental Pathology, Toxicology and Oncology, vol. 14, no. 3-4, pp. 173-180, 1995.

[150] B. Frei, T. M. Forte, B. N. Ames, and C. E. Cross, "Gas phase oxidants of cigarette smoke induce lipid peroxidation and changes in lipoprotein properties in human blood plasma," Biochemical Journal, vol. 277, no. 1, pp. 133-138, 1991.

[151] G. R. Duthie and J. R. Arthur, "Cigarette smoking as an inducer of oxidative stress," in Exercise and Oxygen Toxicity, K. S. Chandan, L. Packer, and H. Osmo, Eds., pp. 297-317, Elsevier Science, New York, NY, USA, 1994. 
[152] E. Méndez-Álvarez, R. Soto-Otero, I. Sánchez-Sellero, and M. L.-R. Lamas, "In vitro inhibition of catalase activity by cigarette smoke: Relevance for oxidative stress," Journal of Applied Toxicology, vol. 18, no. 6, pp. 443-448, 1998.

[153] H. A. Nadiger, C. A. Mathew, and B. Sadasivudu, "Serum malanodialdehyde (TBA reactive substance) levels in cigarette smokers," Atherosclerosis, vol. 64, no. 1, pp. 71-73, 1987.

[154] G. J. Handelman, L. Packer, and C. E. Cross, "Destruction of tocopherols, carotenoids, and retinol in human plasma by cigarette smoke," The American Journal of Clinical Nutrition, vol. 63, no. 4, pp. 559-565, 1996.

[155] C. E. Cross, A. van der Vliet, and J. P. Eiserich, "Cigarette smokers and oxidant stress: a continuing mystery," The American journal of clinical nutrition, vol. 67, no. 2, pp. 184-185, 1998.

[156] D. Lapenna, S. de Gioia, A. Mezzetti et al., "Cigarette smoke, ferritin, and lipid peroxidation," American Journal of Respiratory and Critical Care Medicine, vol. 151, no. 2, pp. 431-435, 1995.

[157] A. M. Preston, "Cigarette smoking-nutritional implications," Progress in Food and Nutrition Science, vol. 15, no. 4, pp. 183217, 1991.

[158] M.-J. Hosseini, P. Naserzadeh, A. Salimi, and J. Pourahmad, "Toxicity of cigarette smoke on isolated lung, heart, and brain mitochondria: induction of oxidative stress and cytochrome c release," Toxicological and Environmental Chemistry, vol. 95, no. 9, pp. 1624-1637, 2013.

[159] Y.-M. Yang and G.-T. Liu, "Injury of mouse brain mitochondria induced by cigarette smoke extract and effect of vitamin $\mathrm{C}$ on it in vitro," Biomedical and Environmental Sciences, vol. 16, no. 3, pp. 256-266, 2003.

[160] K. Anbarasi, G. Vani, and C. S. S. Devi, "Protective effect of bacoside A on cigarette smoking-induced brain mitochondrial dysfunction in rats," Journal of Environmental Pathology, Toxicology and Oncology, vol. 24, no. 3, pp. 225-234, 2005.

[161] A. E. Speck, D. Fraga, P. Soares et al., "Cigarette smoke inhibits brain mitochondrial adaptations of exercised mice," Neurochemical Research, vol. 36, no. 6, pp. 1056-1061, 2011.

[162] J. R. Pauly and T. A. Slotkin, "Maternal tobacco smoking, nicotine replacement and neurobehavioural development," Acta Paediatrica, vol. 97, no. 10, pp. 1331-1337, 2008.

[163] M. Steinlin, "Cerebellar disorders in childhood: cognitive problems," Cerebellum, vol. 7, no. 4, pp. 607-610, 2008.

[164] K. Anbarasi, G. Vani, K. Balakrishna, and C. S. Devi, "Effect of bacoside A on membrane-bound ATPases in the brain of rats exposed to cigarette smoke," Journal of Biochemical and Molecular Toxicology, vol. 19, no. 1, pp. 59-65, 2005.

[165] H. Rauchova, J. Ledvinkova, M. Kalous, and Z. Drahota, "The effect of lipid peroxidation on the activity of various membrane-bound ATPases in rat kidney," International Journal of Biochemistry and Cell Biology, vol. 27, no. 3, pp. 251-255, 1995.

[166] J. H. Sisson, D. J. Tuma, and S. I. Rennard, "Acetaldehydemediated cilia dysfunction in bovine bronchial epithelial cells," The American Journal of Physiology - Lung Cellular and Molecular Physiology, vol. 260, no. 2, part 1, pp. L29-L36, 1991.

[167] G. J. Lees, "Inhibition of sodium-potassium-ATPase: a potentially ubiquitous mechanism contributing to central nervous system neuropathology," Brain Research Reviews, vol. 16, no. 3 , pp. 283-300, 1991.

[168] A. Y. Xiao, L. Wei, S. Xia, S. Rothman, and S. P. Yu, "Ionic mechanism of ouabain-induced concurrent apoptosis and necrosis in individual cultured cortical neurons," Journal of Neuroscience, vol. 22, no. 4, pp. 1350-1362, 2002.
[169] A. K. Singh, "Early developmental changes in intracellular $\mathrm{Ca}^{2+}$ stores in rat brain," Comparative Biochemistry and Physiology Part A: Molecular and Integrative Physiology, vol. 123, no. 2, pp. 163-172, 1999.

[170] A. Zaidi and M. L. Michaelis, "Effects of reactive oxygen species on brain synaptic plasma membrane $\mathrm{Ca}^{2+}$-ATPase," Free Radical Biology and Medicine, vol. 27, no. 7-8, pp. 810-821, 1999.

[171] M. Brownlee, "Advanced protein glycosylatlon in diabetes and aging," Annual Review of Medicine, vol. 46, pp. 223-234, 1995.

[172] M. Brownlee, "Negative consequences of glycation," Metabolism, vol. 49, no. 2, pp. 9-13, 2000.

[173] P. K. Janicki, J. L. Horn, G. Singh, W. T. Franks, and J. J. Franks, "Diminished brain synaptic plasma membrane $\mathrm{Ca}^{2+}$-ATPase activity in rats with streptozocin-induced diabetes: association with reduced anesthetic requirements," Life Sciences, vol. 55, no. 18, pp. PL359-PL364, 1994.

[174] T. C. Squier and D. J. Bigelow, "Protein oxidation and agedependent alterations in calcium homeostasis," Frontiers in Bioscience, vol. 5, pp. D504-D526, 2000.

[175] N. Nedeljkovic, G. Nikezic, A. Horvat, S. Pekovic, M. Stojiljkovic, and J. V. Martinovic, "Properties of Mg(2+)-ATPase rat brain synaptic plasma membranes," General Physiology and Biophysics, vol. 17, pp. 3-13, 1998.

[176] A. Grochowalska and R. Bernat, "Adaptacja aktywności ATPaz synaptosomów różnych obszarów mózgu w hipoksji, modyfikowanej wpływem adrenergicznym i gabaergicznym (Adaptation of ATP-ase activity in synaptosomes of various cerebral regions in hypoxia, modified by adrenergic and gabaergic influences)," Nowiny Lekarskie, vol. 66, no. 4, pp. 397-412, 1997.

[177] R. Vink, T. K. McIntosh, and A. I. Faden, "Magnesium in central nervous system," in Neuroscience Year, G. Adelman, Ed., Supplement 1 to the Encyclopedia of Neuroscience, pp. 93-94, Birkhäuser, Boston, Mass, USA, 1989.

[178] H. Haga, "Effects of dietary magnesium supplementation on diurnal variations of blood pressure and plasma $\mathrm{Na}^{+}, \mathrm{K}^{+}$ATPase activity in essential hypertension," Japanese Heart Journal, vol. 33, no. 6, pp. 785-800, 1992.

[179] A. Rajpurkar, Y. Jiang, C. B. Dhabuwala, J. C. Dunbar, and H. $\mathrm{Li}$, "Cigarette smoking induces apoptosis in rat testis," Journal of Environmental Pathology, Toxicology and Oncology, vol. 21, no. 3, pp. 243-248, 2002.

[180] A. J. Blaschke, J. A. Weiner, and J. Chun, "Programmed cell death is a universal feature of embryonic and postnatal neuroproliferative regions throughout the central nervous system," The Journal of Comparative Neurology, vol. 396, no. 1, pp. 39-50, 1998.

[181] T. S. Roy, J. E. Andrews, F. J. Seidler, and T. A. Slotkin, "Nicotine evokes cell death in embryonic rat brain during neurulation," Journal of Pharmacology and Experimental Therapeutics, vol. 287, no. 3, pp. 1136-1144, 1998.

[182] R. Garrido, K. King-Pospisil, K. W. Son, B. Hennig, and M. Toborek, "Nicotine upregulates nerve growth factor expression and prevents apoptosis of cultured spinal cord neurons," Neuroscience Research, vol. 47, no. 3, pp. 349-355, 2003.

[183] K. Anbarasi, G. Kathirvel, G. Vani, G. Jayaraman, and C. S. Shyamala Devi, "Cigarette smoking induces heat shock protein $70 \mathrm{kDa}$ expression and apoptosis in rat brain: modulation by bacoside A," Neuroscience, vol. 138, no. 4, pp. 1127-1135, 2006.

[184] S. Dwivedi, R. Nagarajan, K. Hanif, H. H. Siddiqui, C. Nath, and R. Shukla, "Standardized extract of Bacopa monniera attenuates okadaic acid induced memory dysfunction in rats: effect on 
Nrf2 pathway," Evidence-Based Complementary and Alternative Medicine, vol. 2013, Article ID 294501, 18 pages, 2013.

[185] R. D. Shytle, A. A. Silver, R. J. Lukas, M. B. Newman, D. V. Sheehan, and P. R. Sanberg, "Nicotinic acetylcholine receptors as targets for antidepressants," Molecular Psychiatry, vol. 7, no. 6, pp. 525-535, 2002.

[186] M. B. Newman, G. W. Arendash, R. D. Shytle, P. C. Bickford, T. Tighe, and P. R. Sanberg, "Nicotine's oxidative and antioxidant properties in CNS," Life Sciences, vol. 71, no. 24, pp. 2807-2820, 2002.

[187] G. N. Neigh, K. Karelina, E. R. Glasper et al., "Anxiety after cardiac arrest/cardiopulmonary resuscitation: exacerbated by stress and prevented by minocycline," Stroke, vol. 40, no. 11, pp. 3601-3607, 2009.

[188] P. Casolini, A. Catalani, A. R. Zuena, and L. Angelucci, "Inhibition of COX-2 reduces the age-dependent increase of hippocampal inflammatory markers, corticosterone secretion, and behavioral impairments in the rat," Journal of Neuroscience Research, vol. 68, no. 3, pp. 337-343, 2002. 


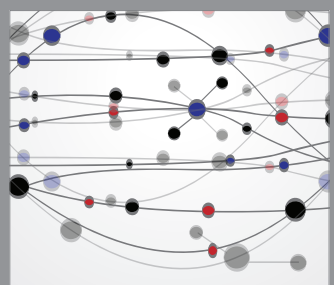

The Scientific World Journal
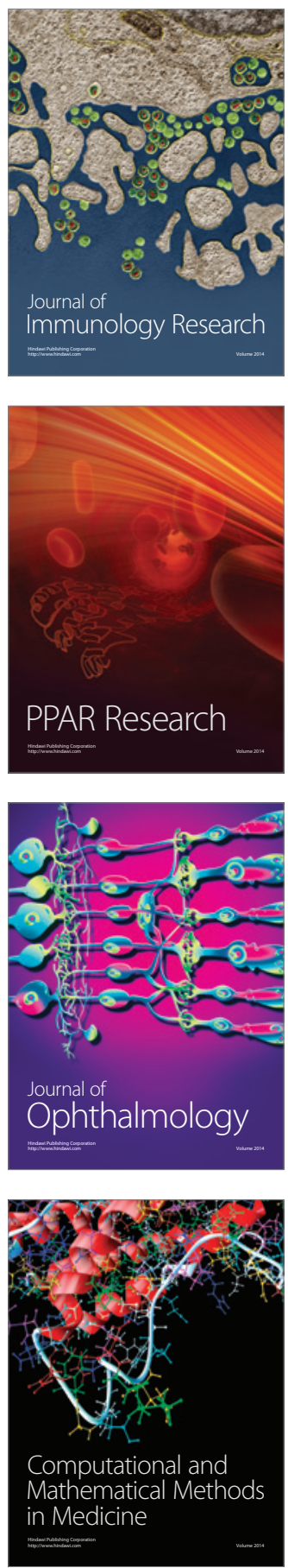

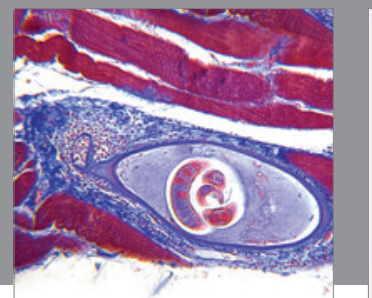

Gastroenterology

Research and Practice
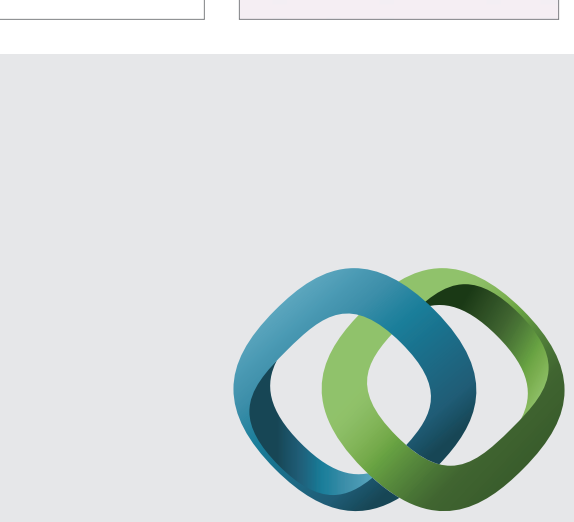

\section{Hindawi}

Submit your manuscripts at

http://www.hindawi.com
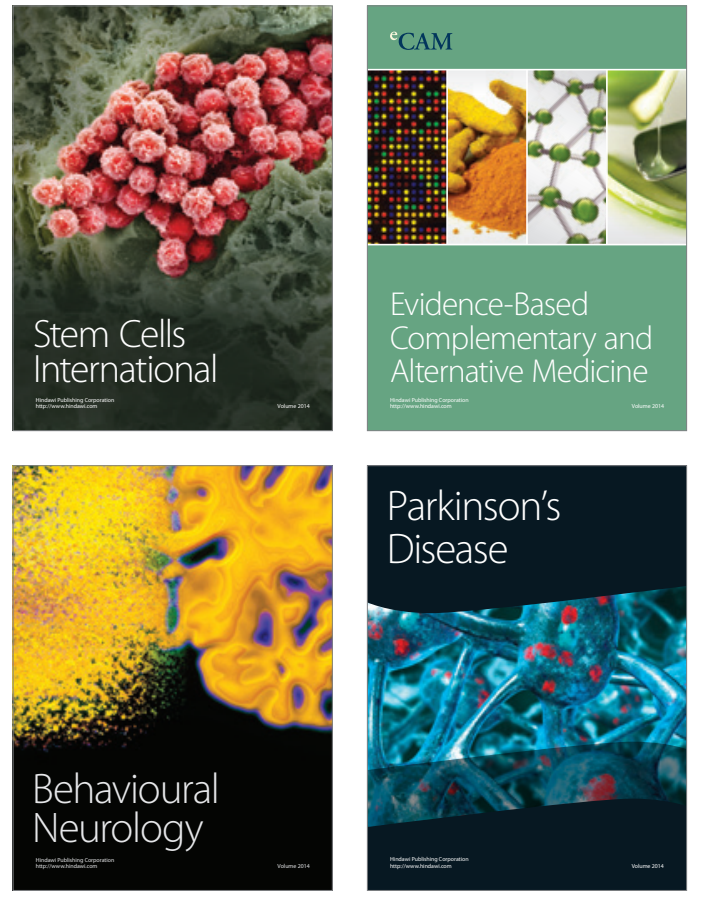
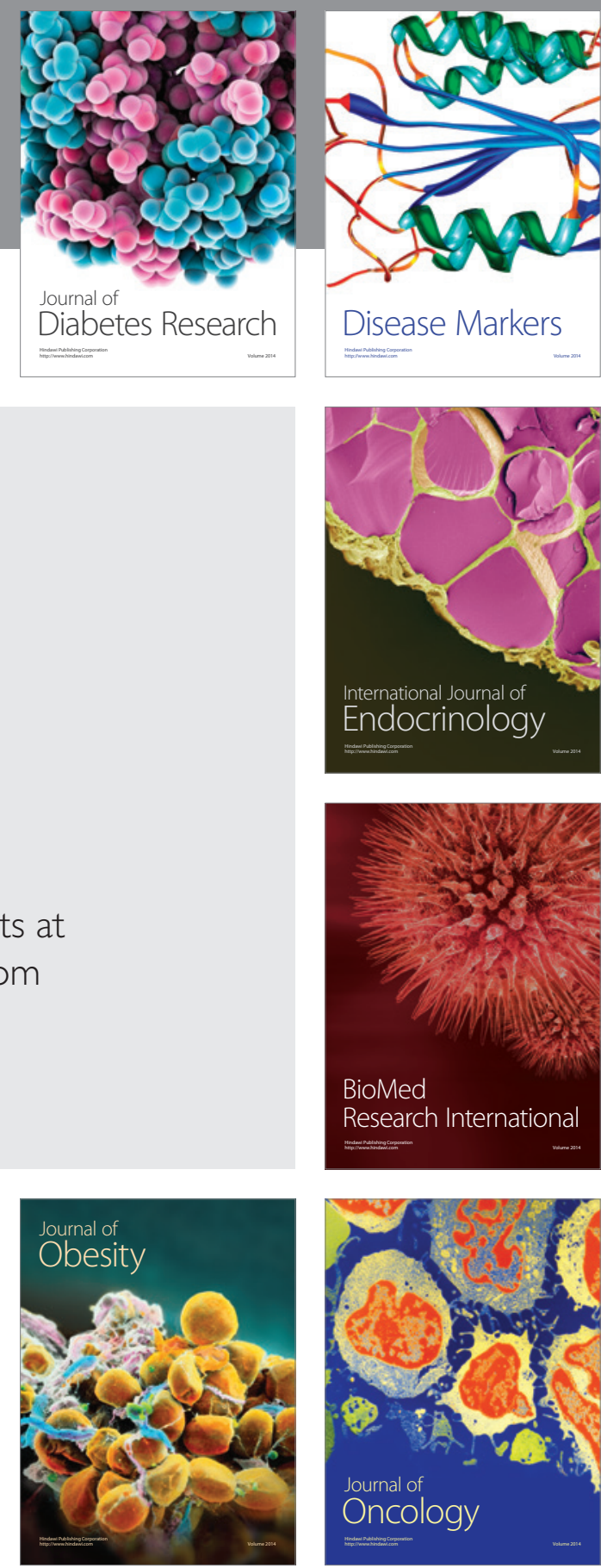

Disease Markers
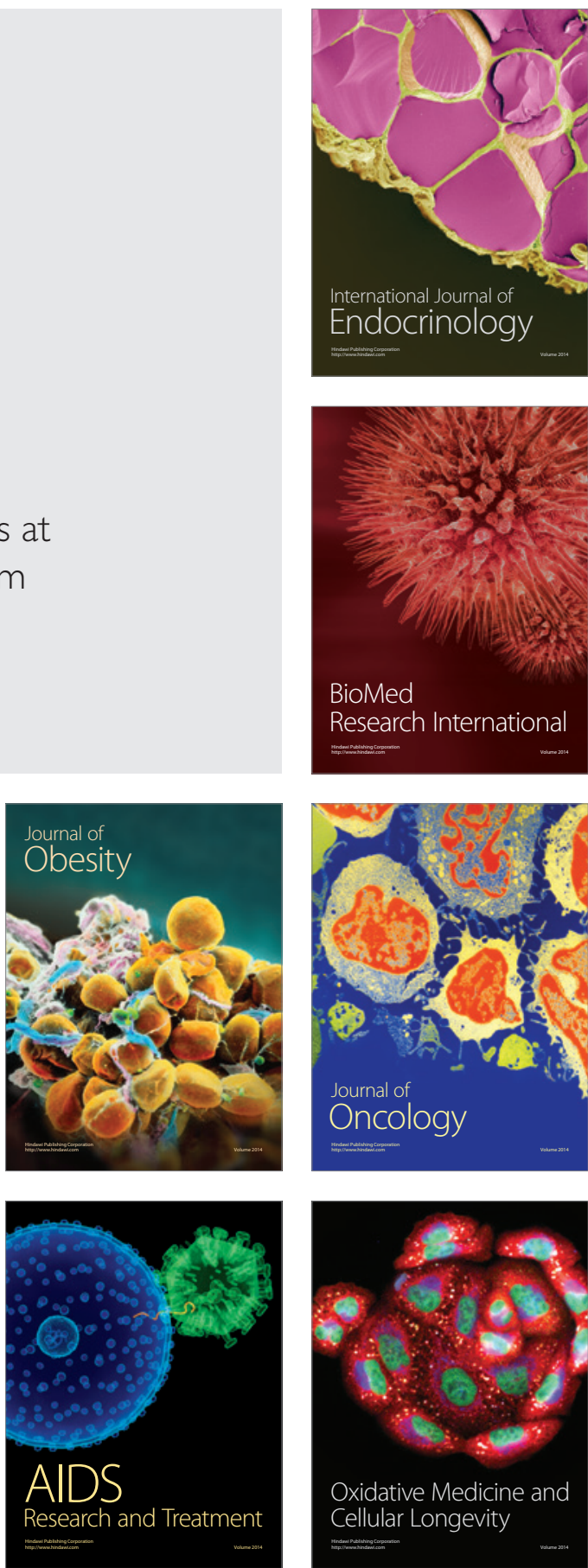